\title{
A Kuiper Belt Object Orbiter Enabled By 10 kW Kilopower Electric Propulsion
}

\author{
Steven Oleson, ${ }^{*}$ John Dankanich, ${ }^{\dagger}$ David Grantier, ${ }^{\star}$ Mike Martini, ${ }^{\S}$ Joe Warner ${ }^{* *}$ and Glenn L. Williams ${ }^{\dagger \dagger}$ \\ NASA Glenn Research Center, Cleveland, Ohio 44135 \\ Paul Schmitz, ${ }^{*}$ Anthony Colozza, ${ }^{\S}$ James Fittje, $^{* * *}$ and Thomas Packard ${ }^{\dagger \dagger}$ \\ Vantage Partners, LLC, Brook Park, Ohio 44142 \\ John Gyekenyesi+t* \\ ZIN Technologies, Middleburg Heights, Ohio 44130
}

\begin{abstract}
Recently, the New Horizons spacecraft flew by the Kuiper Belt Object Ultima Thule 13 years after launch. While flybys are a necessary 'first look' at the object in question a more comprehensive evaluation of the object will require an orbiter. Due to these object's low mass a chemical propulsion system is not a viable option for entering their shallow gravity wells. The Dawn mission showed that solar electric propulsion is significantly better at the task of reaching low mass objects, but at Kuiper belt distances solar power is not a viable choice. A small nuclear reactor based on the recent kilopower ground test could provide $1-10 \mathrm{~kW}$ of power for an electric propulsion system. The NASA Compass Team developed a Nuclear Electric Propulsion Kuiper Belt Object Orbiter to explore what a vehicle would look like to orbit these deep space objects.
\end{abstract}

\section{I.Introduction}

Both radioisotope and nuclear fission power systems are viable for deep space operations ( $>5 \mathrm{AU})$. In the interest of future technology development it is important to identify where one would switch from the use of radioisotope to nuclear fission power systems. The Kuiper Belt Object Orbiter (KBOO) design reference missions (DRMs) was chosen to compare the use of RPS and Nuclear sources for the same science mission. This comparison will provide technologists not only with the ability to identify the challenges in using each system but also provide mission requirements for future developments.

\section{A. Background}

In 2009 the Compass team conducted a Radioisotope Power System (RPS) Sponsored Flagship Radioisotope Electric Propulsion (REP) study for a KBOO utilizing a $3 \mathrm{~kW}$ NASA Evolutionary Xenon Thruster (NEXT) ion propulsion system. ${ }^{1}$ The Nuclear Electric Propulsion (NEP) Kuiper Belt Object Orbiter (KBOO) study was performed for comparison purposes. The NEP KBOO study utilized the same $16 \mathrm{yr}$ transit mission, same science payload, same upper stage Delta IV Heavy (DIVH) and Star 63 launcher as the REP design.

\footnotetext{
* Compass Lead, AIAA Senior Member.

${ }^{\dagger}$ Mission Analyst, AIAA Senior Member.

$\$$ Systems Engineering, nonmember.

$\S$ Systems Engineering, Senior Member.

** Currently retired, Communications Analyst, Department Name, nonmember.

† Currently retired, Glenn L. Williams, nonmember.

$\$$ Nuclear Power Analyst, nonmember.

$\S \S$ Thermal Analyst, nonmember.

*** Propulsion Analyst, Senior Member.

t† CAD Analyst, nonmember.

$\$$ Structural Analyst, nonmember.
} 


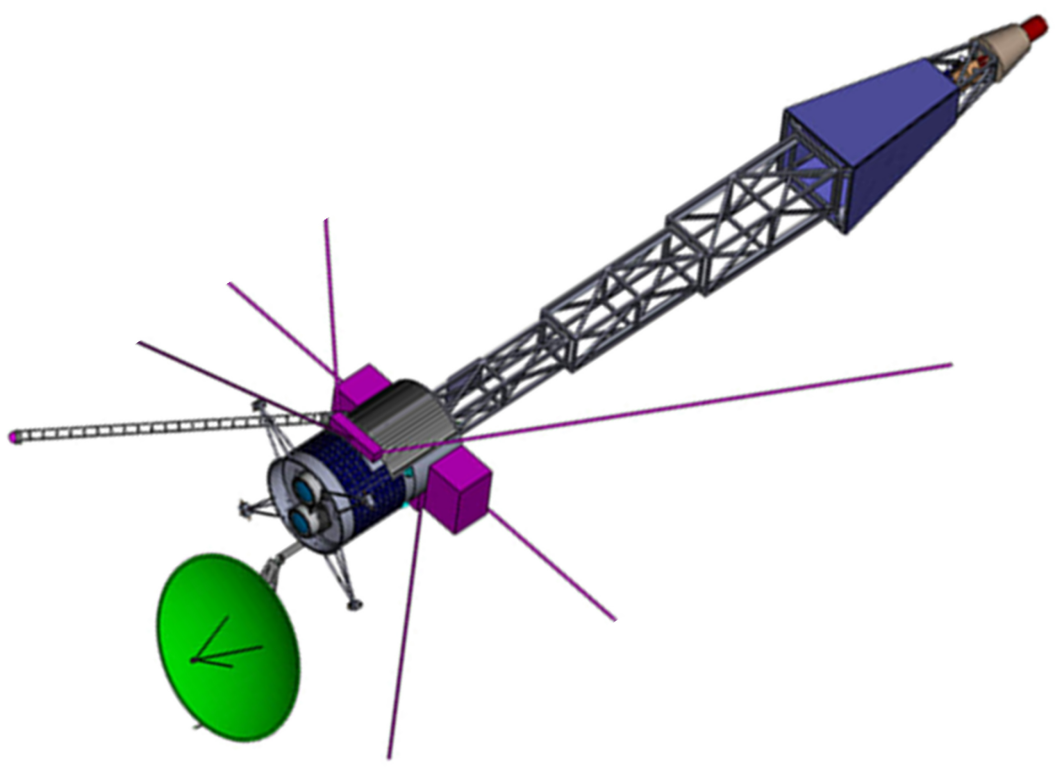

Figure 1. NEP KBOO spacecraft (S/C).

Recent ground tests demonstrated a $1 \mathrm{~kW}$ 'Kilopower' system is both simple and viable for future space missions. ${ }^{2,3}$ Combining a fission power system, leveraged from the kilopower demonstration, with the NEXT ion propulsion system at $7 \mathrm{~kW}$ enables orbiting very deep space objects including Kuiper Belt objects (KBOs). Given the ample power available when NEP is not operating it was found that both higher power active science instruments could be used as well as high data rate communications to return the data quickly (instead of months required by the power limited New Horizons S/C. This paper will detail the $10 \mathrm{~kW}$ e class NEP vehicle design including mission, Concept of Operations (CONOPS), science and subsystem designs.

\section{B. Assumptions and Requirements}

The assumptions and requirements that drove the design, including those that were known prior to starting the Compass design study session, are shown in Table 1. This table also calls out trades that were considered during the course of the design study, and off-the-shelf (OTS) components that were used when possible.

\section{Study Growth and Margins}

For this study, the Compass team used the JPL guidelines for growth in both system level mass growth allowance (MGA) and launch vehicle (LV) margin.

- No LV margin

- $43 \%$ mass growth at system level

- $30 \%$ power margin (except $5 \%$ for NEP power to electric thrusters)

- $30 \%$ data margin

\section{Redundancy Assumptions}

The $\mathrm{S} / \mathrm{C}$ is designed to be single fault tolerant in the design of the subsystems, wherever possible. The exceptions to this are the reactor core, propellant tanks and science instruments.

\section{E. Mission Description}

The mission was designed to rendezvous with and orbit a representative KBO designated as 2001-XH255. This $\mathrm{KBO}$ was determined to be representative of a class of objects that could be explored within a similar mission profile. In order to keep mission flight times reasonable, a high outbound characteristic energy $\left(C_{3}\right)$ is combined with electric propulsion thrusting and a Jupiter gravity assist. The $\mathrm{S} / \mathrm{C}$ arrives at the target after a 16 -yr interplanetary flight.

Table 1. Assumptions and Study Requirements 


\begin{tabular}{|c|c|c|}
\hline Subsystem area & Assumptions and study requirements & Critical trades \\
\hline Top-level & $\begin{array}{l}\text { NEP Orbiter to Orbit KBO (flyby Jupiter). Orbit for } 1 \mathrm{yr} \text {, option to } \\
\text { land at EOM } \\
\text { FOMs: Probe Mass, complexity, science } \\
\text { Science: } 230 \mathrm{~W}, 475 \mathrm{~Gb}, 5 \mathrm{hr} \text { science orbit, } 635 \mathrm{kbps} \text {, map in } 1 \text { month }\end{array}$ & $\mathrm{KBO}$ to be traded \\
\hline System & $\begin{array}{l}\text { OTS equipment where possible, recommend TRL } 3 \text { or over technology } \\
\text { for performance improvement } \\
\text { Mass Growth per updated ANSI/AIAA R-020A-19994 (add growth to } \\
\text { make system level } 43 \% \text {, per JPL practices) }\end{array}$ & Deployable or fixed S/C \\
\hline $\begin{array}{l}\text { Mission and } \\
\text { operations }\end{array}$ & $\begin{array}{l}\text { NEP system, } 16 \text { yr for Probe to reach KBO } \\
\text { Probe provide ACS for all coasting, commands ion thruster gimbal, } \\
\text { solar array (SA) pointing }\end{array}$ & Trading upper stages for DIVH \\
\hline $\begin{array}{l}\text { AD\&C } \\
(\mathbf{L V})\end{array}$ & $\begin{array}{l}\text { DIVH with upper stage, } \mathrm{C}_{3} 80-100 \mathrm{~km}^{2} / \mathrm{s}^{2} \\
\text { Adapter: } 63 \mathrm{in} . \\
\text { Launch Loads: } 4-5 \mathrm{gs} \text { axial, more if solid upper stage used }(\sim 12 \mathrm{gs})\end{array}$ & Trading Adapter choices \\
\hline Propulsion & $\begin{array}{l}1 \text { Active } 7 \mathrm{~kW} \text { NEXT Ion engine with } 1 \text { cold spare, } 2 \text { PPUs } \\
\left(1 \text { is spare, Two-axis range of motion: } \pm 19^{\circ}, \pm 17^{\circ} \text {, single spherical }\right. \\
\text { xenon }(\mathrm{Xe}) \text { tank }\end{array}$ & $\begin{array}{l}\text { Existing COPV Xe Tanks or stretch } \\
\text { existing design? } \\
\text { Ion Engine location (gimbal } \\
\text { interference, adapter clearance, } \\
\text { contamination/ damage from } \\
\text { separation system) }\end{array}$ \\
\hline $\begin{array}{l}\text { Power } \\
\text { C\&DH }\end{array}$ & $\begin{array}{l}\text { Kilopower Fission System (with } 500 \text { W housekeeping) } \\
\text { 2-fault tolerant, } 100 \text { GB storage }\end{array}$ & $\begin{array}{l}\text { Power conversion options } \\
\text { Trading add RIU }\end{array}$ \\
\hline \multicolumn{3}{|c|}{ Communications $67 \mathrm{kbps}$ (Ka band, $200 \mathrm{~W}$ output) } \\
\hline $\begin{array}{l}\text { Thermal and } \\
\text { environment }\end{array}$ & $\begin{array}{l}\text { Body mounted radiator (main loads } 500 \mathrm{Wth} \text { from PPU) } \\
\text { Tank heater from RPS waste heat or electric heaters } \\
\text { Radiation level (should not be a factor), micrometeoroid environment? }\end{array}$ & Trading \\
\hline Mechanisms & $\begin{array}{l}\text { 2- thruster gimbals, Two-axis range of motion: } \pm 19^{\circ}, \pm 17^{\circ} \text {, Single axis } \\
\text { SA drives, Science deployments } \\
\text { Probe/ Stage Separation System: Lightband }\end{array}$ & Trading direct drive \\
\hline Structures & $\begin{array}{l}\text { Primary: Thrust Tube } 1.6 \mathrm{~m} \text { diameter, Al-Li, Carry } \sim 3000 \mathrm{~kg} \text { Probe, } \\
\text { Secondary: } 4 \% \text { of probe components }\end{array}$ & Reactor deployment mechanisms \\
\hline
\end{tabular}

1. Mission Analysis Assumptions

The mission is assumed to launch on a DIVH LV with a Star-63F high-energy upper stage. No margin is included on the LV performance at the mission level but is instead carried at the system level. Once in space, the power system is assumed to deliver $6.891 \mathrm{~kW}$ into the propulsion system to operate the NEXT ion thruster, which operates with an efficiency of 0.704 and an Isp of $4188 \mathrm{~s}$. While thrusting, a $95 \%$ duty cycle is assumed, leaving time for communication and other nonthrusting activities. No forced coasts are imposed immediately after launch or before arrival to the target, but optimal coasting is included when appropriate.

2. KBO Target

The Kuiper belt is a region of the Solar System beyond the planets extending from the orbit of Neptune (at $30 \mathrm{AU}$ ) to approximately $55 \mathrm{AU}$ from the Sun. It is similar to the main asteroid belt but much wider and containing much more mass. There are over 70,000 objects of greater than $100 \mathrm{~km}$ diameter to be found within the belt. Although similar to the asteroid belt whose inhabitants are composed primarily of rock and metal, the KBOs are thought to be composed largely of frozen ices, such as methane, ammonia and water. The Kuiper belt is also the home to Pluto.

This study's goal was to design an NEP S/C to send a science payload to orbit one of the KBOs. The targets were limited to KBO's with perihelion $>32$ AU to ensure the surface ice has never been heated and modified from its primitive state. A single $\mathrm{KBO}$ was taken as representative, but other potential targets may exist with similar mission profiles. The primary target chosen was the object designated 2001-XH255. This target was chosen as representative $(\mathrm{a}=34.8 \mathrm{AU}, \mathrm{e}=0.07)$. Figure 2 shows a plot of orbit eccentricity as a function of semimajor axis for a population of KBOs that are found with similar orbital characteristics. 


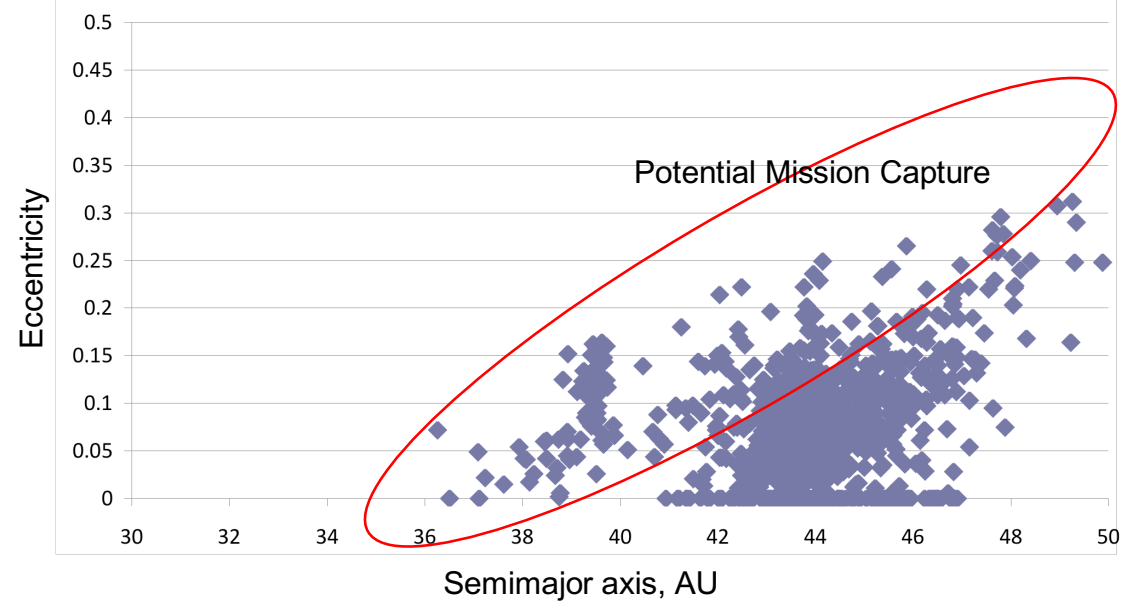

Figure 2. Plot of eccentricity as a function of semimajor axis for a population of potential KBO targets.

3. Mission Analysis Analytic Methods

The low thrust trajectory design for this mission was optimized using the Mission Analysis Low-thrust Trajectory Optimization (MALTO) tool. Mission analysis was performed in an iterative fashion. An initial trajectory to the target was performed using MALTO to get the electric propulsion system propellant loading for the missions. With this propellant, the bottoms-up estimation of the vehicle mass was completed by the team. Once this bottoms-up mass was calculated, the trajectory was rerun in order to provide performance for at least that calculated total wet mass. The mission was iterated until the amount of mass pushed by the electric propulsion (EP) system was greater than or equal to the total wet mass of the vehicle.

This case delivered the bottoms-up wet mass of the KBOO S/C and fit onto the LV being used. For the selected $\mathrm{KBO}$ target the LV is the DIVH with an upper stage which was assumed to be representative of heavy launchers.

4. Mission Details

The mission departs Earth on July 6, 2035, using a DIVH LV and high energy Star-63F upper stage to deliver the $\mathrm{S} / \mathrm{C}$ to a departing $\mathrm{C}_{3}$ of $58 \mathrm{~km}^{2} / \mathrm{s}^{2}$. After $2.2 \mathrm{yr}$ of thrusting, the $\mathrm{S} / \mathrm{C}$ arrives at Jupiter for a gravity assist on September 8,2037 , with a minimum flyby altitude of $370,000 \mathrm{~km}$. A 9.8 -yr cruise period precedes the final $4 \mathrm{yr}$ thrust arc that matches the orbital velocity of the target KBO. Figure 3 shows a plot of the interplanetary trajectory for the mission.

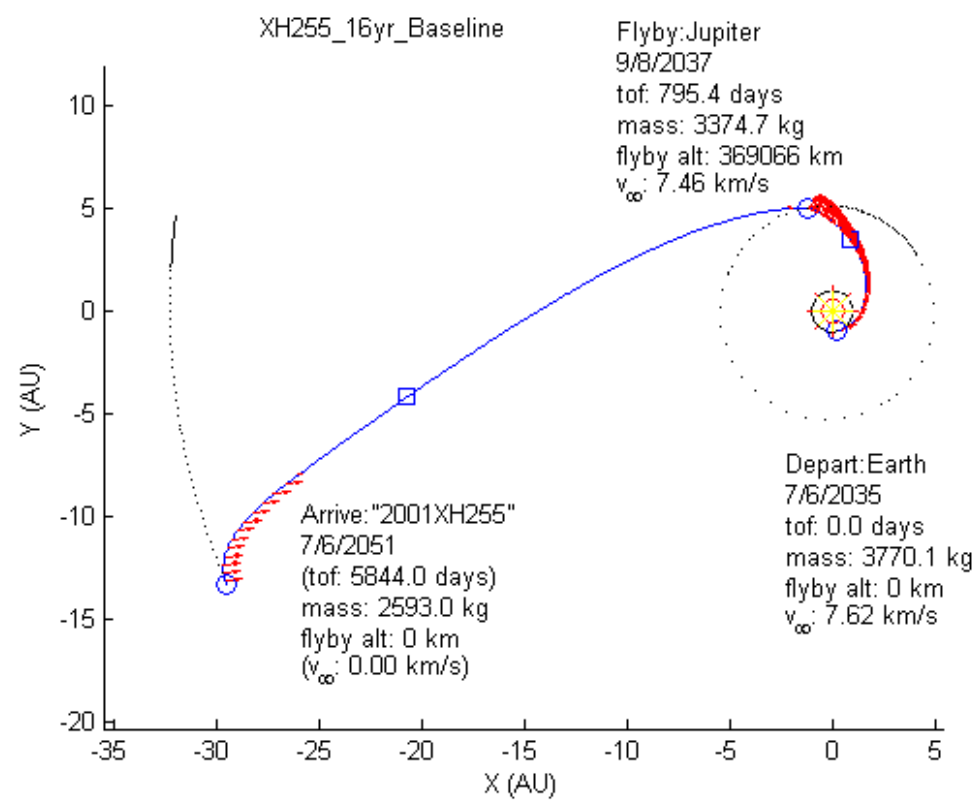

Figure 3. Interplanetary trajectory for the mission. 


\section{Mission $\triangle V$ Details}

The mission design requires a total $\Delta \mathrm{V}$ of $15.4 \mathrm{~km} / \mathrm{s}$ from the primary EP system. Table 2 shows the $\Delta \mathrm{V}$ and propellant required for each phase of the mission. The propellant numbers from the table represent useable masses. An additional percentage (5\% for main, $10 \%$ for ACS) of the usable is carried as margin, which is included in the vehicle inert mass.

Table 2. Mission $\Delta V$ Summary

\begin{tabular}{|c|c|c|c|c|c|c|c|}
\hline $\begin{array}{c}\text { Phase } \\
\text { no. }\end{array}$ & Phase Name & $\begin{array}{c}\text { Pre-Burn } \\
\text { Mass } \\
\text { (kg) }\end{array}$ & $\begin{array}{c}\text { Main } \Delta V \\
(\mathrm{~m} / \mathrm{s})\end{array}$ & $\begin{array}{c}\operatorname{ACS} \Delta V \\
(\mathrm{~m} / \mathrm{s})\end{array}$ & $\begin{array}{c}\text { Main Prop } \\
\text { (kg) }\end{array}$ & $\begin{array}{c}\text { ACS Prop } \\
\text { (kg) }\end{array}$ & $\begin{array}{c}\text { Post Burn } \\
\text { Mass } \\
\text { (kg) }\end{array}$ \\
\hline 1 & Launch & 3700 & & & & & 3700 \\
\hline 2 & Roll Control, Star 63F Burn & 3700 & & 0.2 & & 0.4 & 3699 \\
\hline 3 & EP Thrust, Leg 1 & 3699 & 4547 & & 388 & & 3312 \\
\hline 4 & Momentum Management, Leg 1 Thrusting & 3312 & & 3.4 & & 5.0 & 3307 \\
\hline 5 & Spin Up/Down, Spin Axis Precession & 3307 & & 2.1 & & 3.1 & 3304 \\
\hline 6 & EP Thrust, Leg 2 & 3304 & 10825 & & 765 & & 2538 \\
\hline 7 & Momentum Management, Leg 2 Thrusting & 2538 & & 4.4 & & 5.0 & 2533 \\
\hline 8 & ACS Capture at KBO & 2533 & & 10.0 & & 11.3 & 2522 \\
\hline 9 & Spiral to $100 \mathrm{~km}$ circular orbit & 2522 & 41 & & 3 & & 2519 \\
\hline 10 & Science Mission Momentum Management & 2519 & & 0.3 & & 0.3 & 2519 \\
\hline \multirow[t]{2}{*}{11} & Spiral to $10 \mathrm{~km}$ circular orbit & 2519 & 16 & & 1 & & 2518 \\
\hline & Total & & 15429 & 20.4 & 1157 & 25.0 & \\
\hline
\end{tabular}

\section{F. Launch Vehicle Details}

At the time the mission design was performed the DIVH was the only US heavy launcher in service. Since that time other heavy launchers have flown or are planned to fly which could be used for this mission.

\section{Launch Vehicle Trade Space}

- No launch margin removed

- DIVH adaptor removed, Star 63F payload adaptor still needed

- Baseline LV is the DIVH with Star or Centaur Stage

- Assume DIVH is representative, open up possibility for better vehicle in $20 \mathrm{yr}$

- Launch vehicle contingency $=0 \%$ (will be carried in the $43 \%$ Systems contingency)

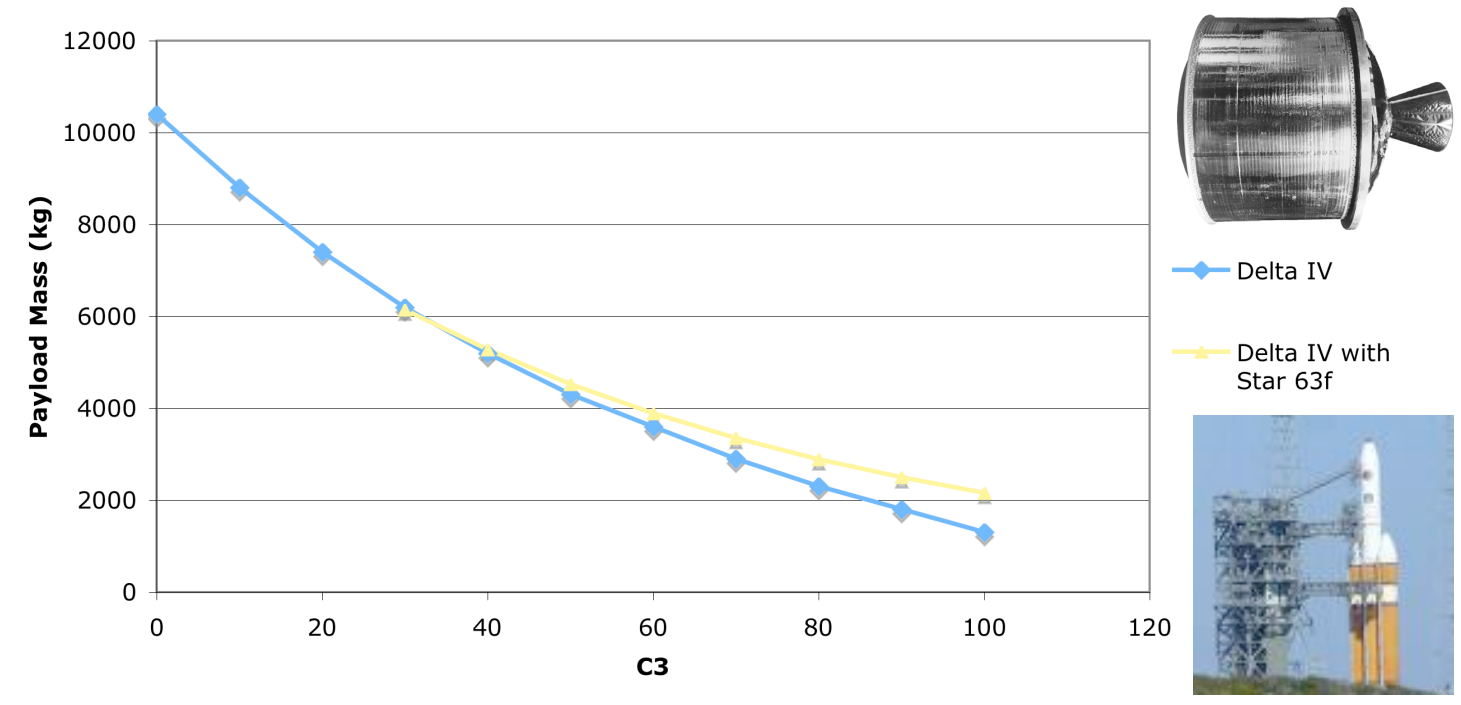

Figure 4. DIVH C3 performance with Star 63F 


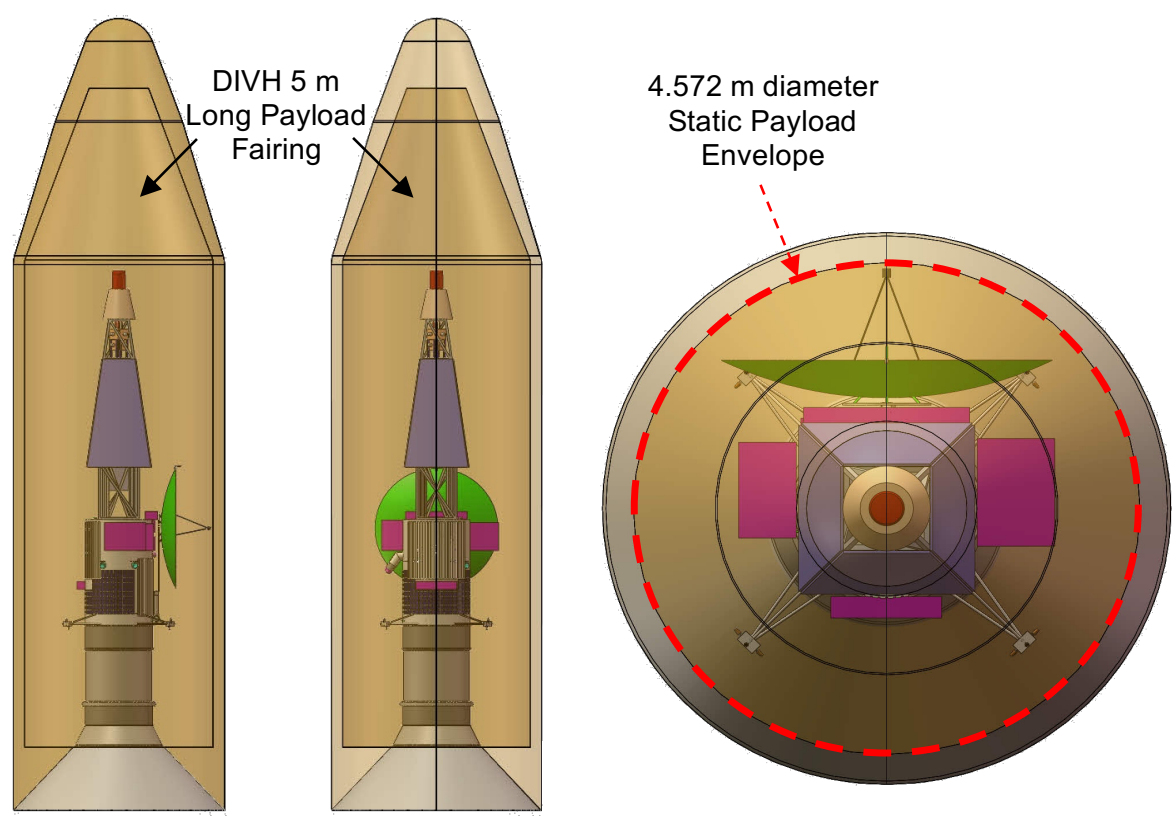

Figure 5. NEP KBOO stowed inside the Payload Fairing.

\section{Payload Fairing Configuration}

The NEP KBOO S/C was designed for launch on a DIVH and packaged inside the DIVH 5-m Long Payload Fairing, which provides a 4.572-m diameter static payload envelope. Figure 5 shows the NEP KBOO stowed inside the selected fairing.

In order to achieve escape velocity, a Star 63F Solid Rocket Motor is required to perform the escape burn. This drove the need for the Long Payload Fairing option as the Star 63F is considered part of the payload and its length must be accounted for in the payload volume. In order to integrate the Star 63F into the entire launch stack, two "payload specific" adaptors are required in addition to the DIVH 1666-5 Payload Attach Fitting (PAF). The first is an adaptor that runs between the 1666-5 PAF and Star 63F that will remain with the LV upon separation from the upper stage. This adaptor is required in order to keep the nozzle of the Star 63F out of the keep-out-zone associated with the 1666-5 PAF and to provide a transition between the slightly different interface diameters provided by each the Star 63F and 1666-5 PAF. The second additional adaptor is located between the Star 63F and the NEP KBOO bus structure and would remain with the Star 63F when jettisoned after the escape burn is performed. This adaptor is required since the interface to the $\mathrm{Star} 63 \mathrm{~F}$ is at the base of the upper dome of its casing thus requiring the upper dome to be surpassed by an adaptor. The complete launch stack for the NEP KBOO mission can be seen in Figure 6 .

In order to fit within the Payload Fairing, many of the components on the NEP KBOO S/C must be stowed for launch and deployed at the proper time after the fairing is jettisoned. These components include the reactor, reactor shield, Stirling converters, power conversion radiator, high and medium gain antennas, ground penetrating radar antennas, plasma wave antennas, and the magnetometer.

The reactor must be deployed in order to provide the proper distance between itself and the nearest electronics contained on the bus (in this case it is the ground penetrating radar at a distance of $12.66 \mathrm{~m}$ ). Deployment of the reactor also allows the bus, deployed high and medium gain antennas, and deployed magnetometer to remain within the shield cone provided by the $11.7^{\circ}$ half-cone angle reactor shield. The reactor, reactor shield, Stirling converters, and power conversion radiators are all fixed in relation to one another and mounted tapered box truss structure that is deployed by a telescoping boom. This telescoping boom contains three box trusses that when deployed provide the proper distance.

The magnetometer is deployed via an astro-mast type deployable truss structure. When deployed, the 5-m long boom is angled towards the aft end (thruster end) of the bus structure putting it within the wider section of the shield cone and keeping at as far away from the bus electronics as possible while staying within the shield cone. The ground penetrating radar and plasma wave antennas are whip antennas and are deployed as such. While these antennas extend outside the shield cone, it was determined that the scatter and potential interference from the reactor were not significant.

Figure 7 shows the transition between the stowed and deployed configurations. 


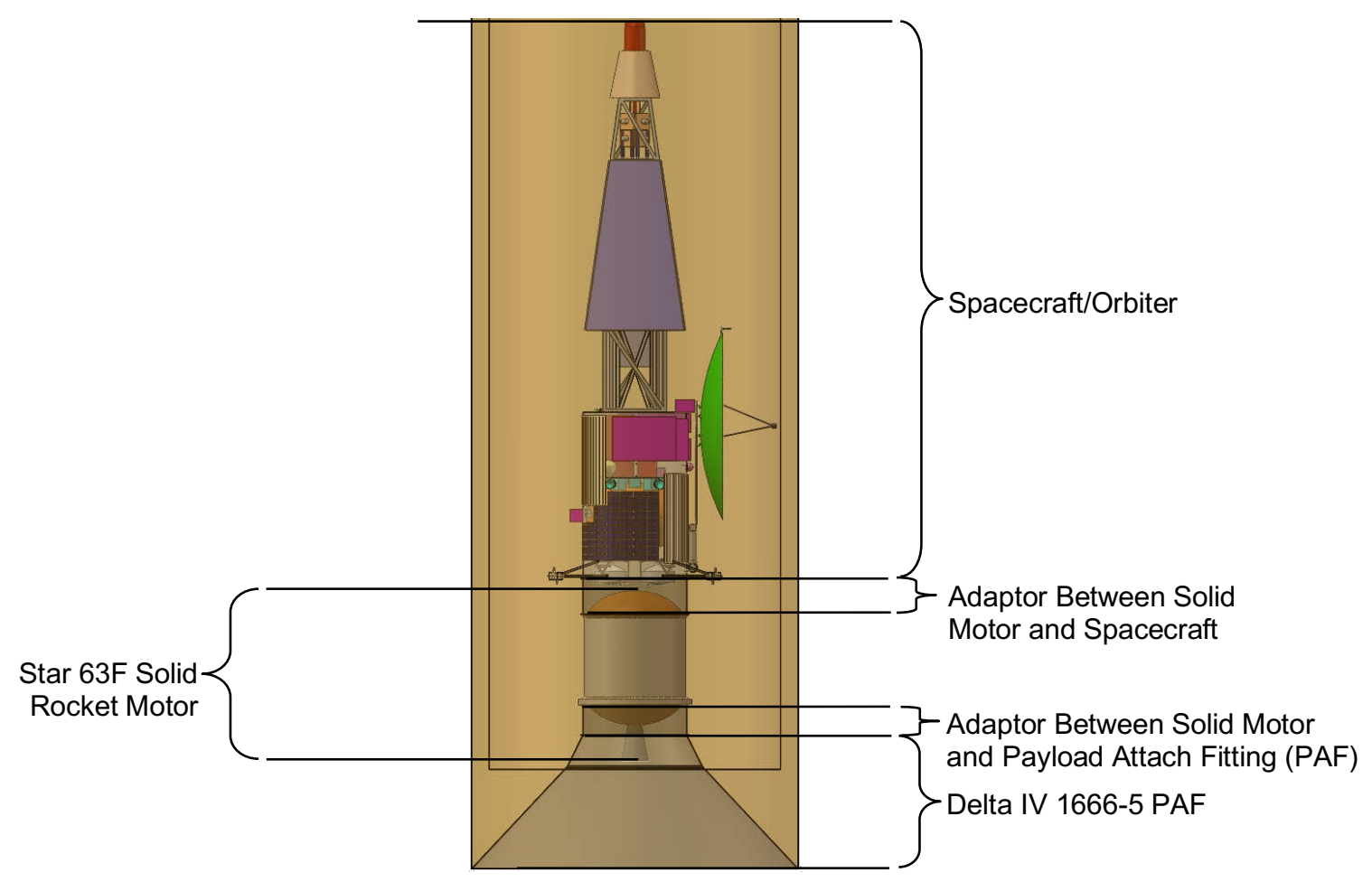

Figure 6. Launch stack for the NEP KBOO mission.

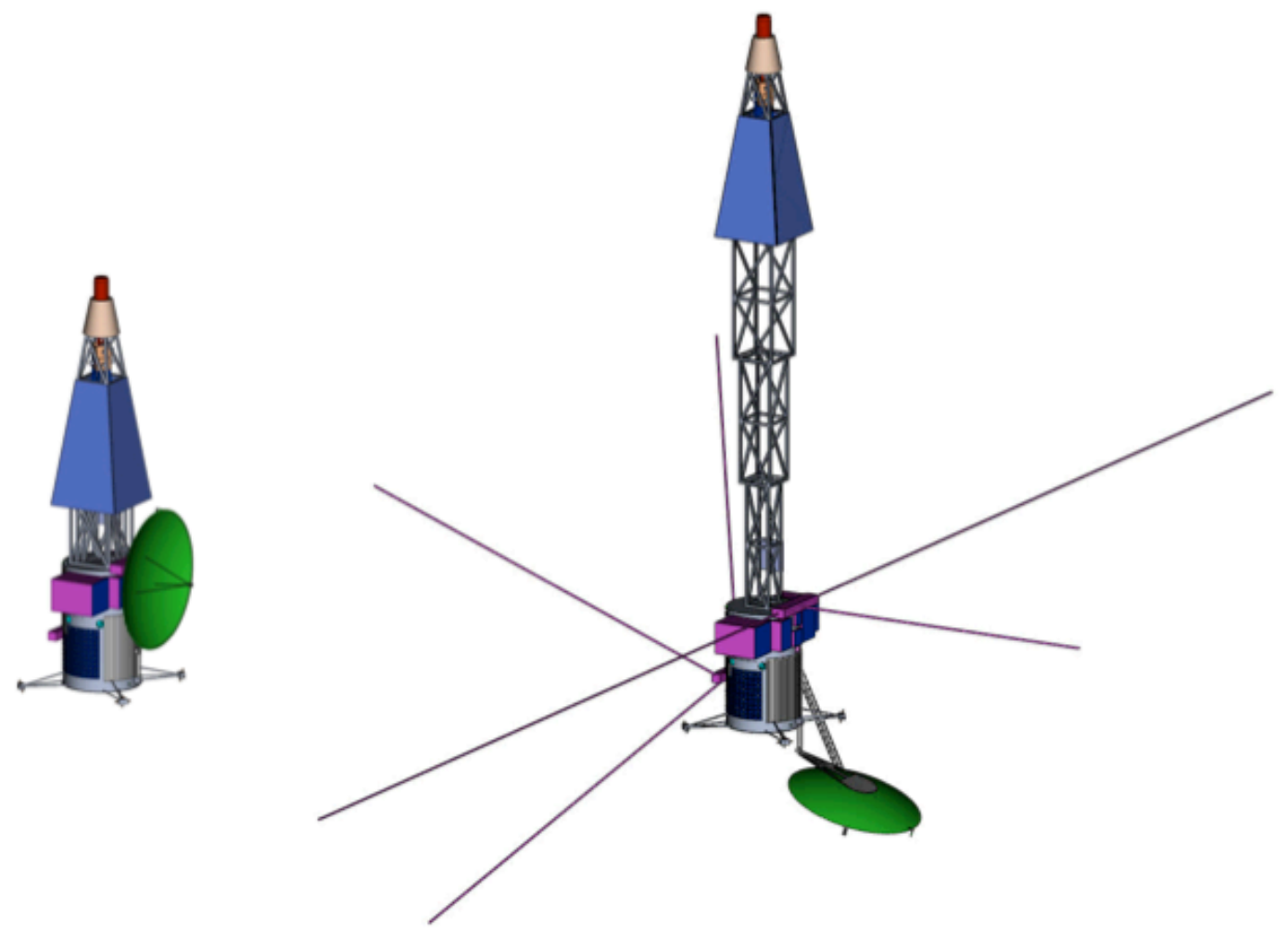

Figure 7. Stowed and deployed configurations of NEP KBOO. 


\section{G. Concept of Operations (CONOPS)}

The CONOPS for the mission allow all the science, mission and subsystem events to be laid out or 'story-boarded' together. This part of the conceptual design cycle is key to deriving requirements, trading options, and discovering potential subsystem interactions. The top level Launch and Delivery CONOPS and the following Science CONOPS events are listed below and pictorially represented in Figure 8.

\section{Launch and delivery CONOPS}

- DIVH launch to parking orbit (LEO, $185 \mathrm{~km})(90 \mathrm{~min})$

- Re-ignite upper stage to burn out then separate

- Burn Star 63F with 3-axis control using TVC/RCS to achieve escape velocity

- Separate star 63F and perform collision avoidance maneuver (CAM) using RCS

- Check out S/C bus (small SA/battery for startup power)

- Start-up reactor

- $\quad$ Prep 1 day, startup takes 2-10 hr and needs $500 \mathrm{~W}$ power

- Check out electric thrusters (1 day)

- Start thrusting (785 days)

- Jupiter flyby (communicate with Earth) (10 days)

- Spin s/c up to 5 rpm using RCS for coasting

- Coast (3607 days) - put S/C to "sleep" slow flat spin 5 rpm (New Horizons)

- Drop NEP power output to $30 \%$ of the nominal and dump heat to the shunt radiator

- Communicate with Earth DSN for $8 \mathrm{hr}$ periods

- Thrusting phase: once a month

- Coast phase: once 6 months

- During arrival final year thrust phase: once a month

- Arrival: once a week

- Science: once a day

- $\quad$ Start thrusting for KBO arrival (1452 days)

- Capture at KBO using RCS thruster

- Initiate Science CONOPS (365 days)

2. Science CONOPS

- Rendezvous from 1000's of km and move to high orbit (several days to measure object mass): $\sim 2$ weeks

- Allow computation of orbit (velocities)

- Initial mapping and spin axis

- Move to low circular orbit $(\sim 100 \mathrm{~km}): \sim 3$ months

- Pointable antenna, accelerometer

- Primary science ( $100 \mathrm{~km}$, options to go lower): 12 months

- $\quad \sim 10$ am low circular orbit to pick up shadows

- Pointable Antenna to allow simultaneous science/communications

- EP spiral down to $10 \mathrm{~km}$ : Ion-Engine Sputtered Ion Mass Spectrometry (IE-SIMS) experiment: $\sim 10$ orbits

- Penetrator experiment

- $10 \mathrm{~kg}$ penetrators from $10 \mathrm{~km}$ : solid motors to cancel velocity and modify free-fall to allow KBOO to see impact: 1-3 day life

- End of mission options

- Raise orbit and deactivate

3. Subsystem Power Requirements

Based on the CONOPS six power modes were developed for operations including NEP activation, NEP thrusting, Coast, and Science. Within each power mode each subsystem determines an average power This Power Equipment List (PEL) is used by the power designer to determine the reactor, power conversion, and commissioning power system sizes. The NEP KBOO PEL is shown in Table 3. 


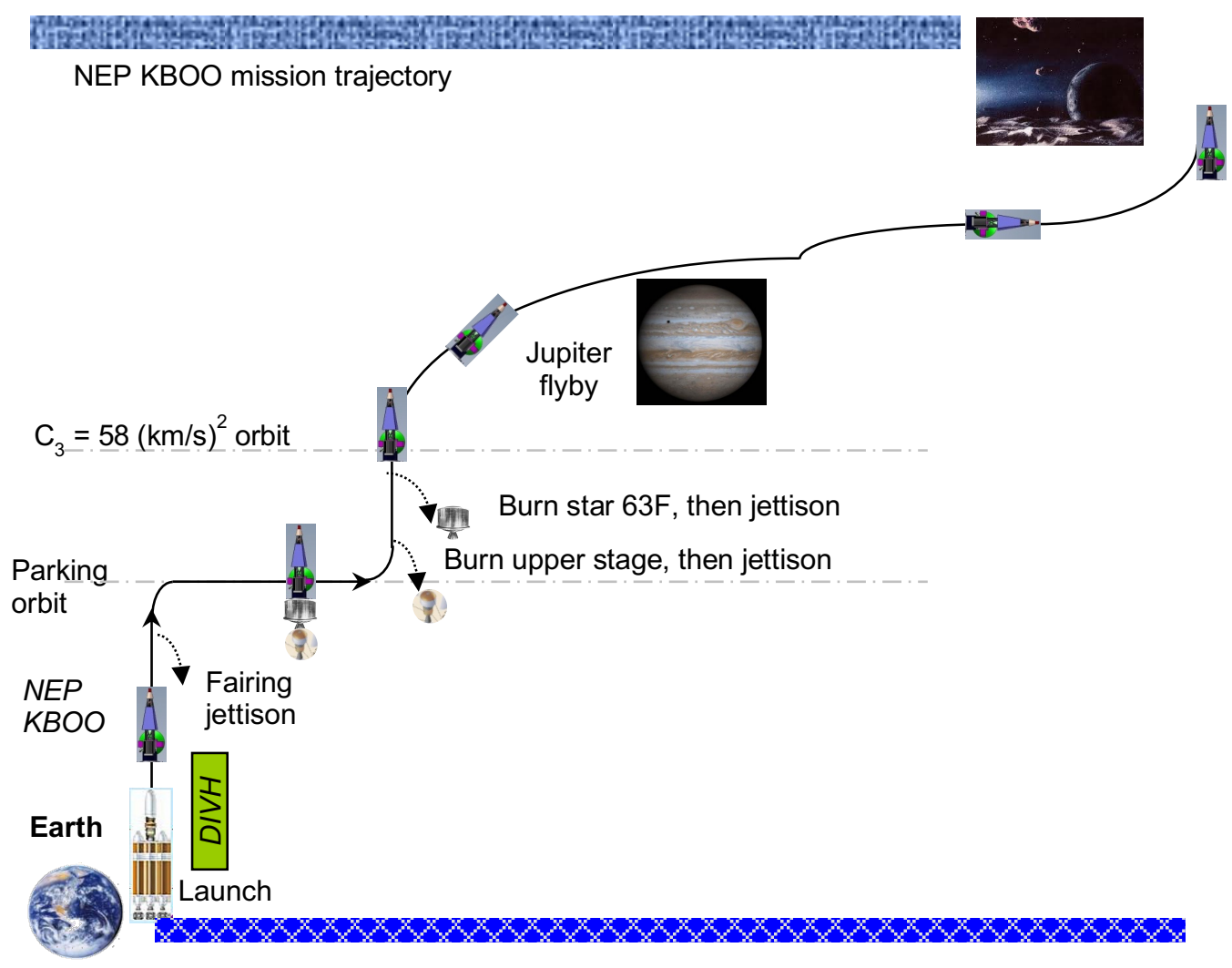

Figure 8. Transit CONOPs

Table 3. NEP KBOO PEL

\begin{tabular}{|c|c|c|c|c|c|c|c|}
\hline Power Mode Name & $\begin{array}{c}\text { Power } \\
\text { Mode } 1 \\
(W) \\
\end{array}$ & $\begin{array}{c}\text { Power } \\
\text { Mode } 2 \\
(W)\end{array}$ & $\begin{array}{c}\text { Power } \\
\text { Mode } 3 \\
(W) \\
\end{array}$ & $\begin{array}{c}\text { Power } \\
\text { Mode } 4 \\
(W) \\
\end{array}$ & $\begin{array}{l}\text { Power } \\
\text { Mode } 5 \\
(W)\end{array}$ & $\begin{array}{c}\text { Power } \\
\text { Mode } 6 \\
(W) \\
\end{array}$ & $\begin{array}{c}\text { Power } \\
\text { Mode } 7 \\
(W)\end{array}$ \\
\hline & Pre-launch & Launch & $\begin{array}{c}\text { NEP } \\
\text { activation \& } \\
\text { checkout }\end{array}$ & Thrusting & Coast & $\begin{array}{l}\text { Science } \\
\text { mission }\end{array}$ & Others \\
\hline Power Mode duration & $5 \mathrm{~min}$ & $120 \mathrm{~min}$ & $10 \mathrm{hr}$ & 2237 days & $\begin{array}{l}3607 \\
\text { days }\end{array}$ & 365 days & 0 days \\
\hline $\begin{array}{l}\text { NEP Kuiper Belt Object Orbiter } \\
\text { (KBOO) vehicle }\end{array}$ & 129.87 & 129.87 & 7548.27 & 7548.27 & 666.27 & 782.27 & 207.27 \\
\hline Science & 10 & 10 & 226 & 226 & 0 & 0 & 0 \\
\hline Attitude Determination and Control & 10 & 10 & 161 & 161 & 56 & 161 & 0 \\
\hline Command \& Data Handling & 44.3 & 44.3 & 55.3 & 55.3 & 44.3 & 55.3 & 55.3 \\
\hline Communications and Tracking & 0 & 0 & 63 & 63 & 414 & 414 & 0 \\
\hline Electrical Power Subsystem & 0 & 0 & 0 & 0 & 0 & 0 & 0 \\
\hline Thermal Control (Non-Propellant) & 15.57 & 15.57 & 15.57 & 15.57 & 15.57 & 15.57 & 15.57 \\
\hline Propulsion (Chemical Hardware) & 0 & 0 & 86.4 & 86.4 & 86.4 & 86.4 & 86.4 \\
\hline Propellant (Chemical) & 0 & 0 & 0 & 0 & 0 & 0 & 0 \\
\hline Propulsion (EP Hardware) & 50 & 50 & 6941 & 6941 & 50 & 50 & 50 \\
\hline Propellant (EP) & 0 & 0 & 0 & 0 & 0 & 0 & 0 \\
\hline Structures and Mechanisms & 0 & 0 & 0 & 0 & 0 & 0 & 0 \\
\hline Total with EP & 129.87 & 129.87 & 7548.27 & 7548.27 & 666.27 & 782.27 & 207.27 \\
\hline$+30 \%$ except EP & 168.83 & 168.83 & 7730.45 & 7730.45 & 851.15 & 1001.2 & 254.45 \\
\hline Waste heat* & 129.87 & 129.87 & 575.77 & 575.77 & 409.3 & 525.3 & 157.27 \\
\hline
\end{tabular}

*Waste heat: no margin applied, include $50 \%$ of the power under communication and tracking 


\section{II.Vehicle Design}

\section{A. Spacecraft Total Mass Summary}

The MEL shown in Table 4 captures the bottoms-up estimation of current best estimate (CBE) and growth percentage that the subsystem designers calculated for each line subsystem. The following sections provide additional detail about the basic and total masses of the different subsystems. Each subsystem will be described in following sections. The MEL shows a required launch mass of almost $3700 \mathrm{~kg}$ with the reactor power system and the Xe propellant each at around $1200 \mathrm{~kg}$. The science was estimated at $100 \mathrm{~kg}$.

Table 4. Top Level NEP KBOO Characteristics

\begin{tabular}{|c|c|c|c|c|}
\hline Main Subsystems & $\begin{array}{l}\text { Basic mass } \\
(\mathrm{kg})\end{array}$ & $\begin{array}{c}\text { Growth } \\
(\mathrm{kg})\end{array}$ & $\begin{array}{l}\text { Total mass } \\
(\mathrm{kg})\end{array}$ & $\begin{array}{c}\text { Aggregate growth } \\
(\%)\end{array}$ \\
\hline Spacecraft Name & 2962.2 & 188.0 & 3150 & \\
\hline Element 1 & 2962.2 & 188.0 & 3150 & $6 \%$ \\
\hline Science & 100.0 & 0.0 & 100 & $0 \%$ \\
\hline Attitude Determination and Control & 25.5 & 1.3 & 27 & $5 \%$ \\
\hline Command and Data Handling & 36.2 & 8.8 & 45 & $24 \%$ \\
\hline Communications and Tracking & 52.9 & 11.4 & 64 & $21 \%$ \\
\hline Electrical Power Subsystem & 1163.5 & 140.5 & 1304 & $12 \%$ \\
\hline Thermal Control (Non-Propellant) & 72.1 & 0.2 & 72 & $0 \%$ \\
\hline Propulsion (Chemical Hardware) & 17.7 & 1.1 & 19 & $6 \%$ \\
\hline Propellant (Chemical) & 28.9 & & 29 & $0 \%$ \\
\hline Propulsion (EP Hardware) & 122.8 & 11.2 & 134 & $9 \%$ \\
\hline Propellant (EP) & 1223.2 & & 1223 & $0 \%$ \\
\hline Structures and Mechanisms & 119.3 & 13.6 & 133 & $11 \%$ \\
\hline Element 1 consumables (for reference) & 0 & & 0 & \\
\hline Estimated S/C Dry Mass (no prop, consumables) & 1710 & 188 & 1898 & $11 \%$ \\
\hline Estimated S/C Wet Mass & 2962 & 188 & 3150 & \\
\hline System Level Growth Calculations Element 1 & & & & Total growth \\
\hline Dry Mass Desired System Level Growth & 1710 & 735 & 2445 & $43 \%$ \\
\hline Additional Growth (carried at system level) & & 547 & & $32 \%$ \\
\hline Total Wet Mass with Growth & 2962 & 735 & 3698 & \\
\hline
\end{tabular}

1. Propellant Calculations

The propellant details are captures in Table 5. The total SEP inert mass includes trapped residuals and propellant margins, as well as all dry masses.

Table 5. Baseline Propellant Details

\begin{tabular}{lc}
\hline \hline \multicolumn{1}{c}{ Element 1: Propellant Details (Chemical) (kg) } \\
\hline Mass, Propellant Total & $\mathbf{2 9}$ \\
Mass, Propellant Useable & 25 \\
Mass, Prop Navigation and Trajectory Margin & 3 \\
Mass, Prop Residuals & 1 \\
\hline \multicolumn{1}{c}{ Propellant Details (EP) (kg) } \\
\hline Mass, Propellant Total & $\mathbf{1 2 2 3}$ \\
Mass, Propellant Useable & 1157 \\
Mass, Prop Navigation and Trajectory Margin & 58 \\
Mass, Prop Residuals & 9 \\
\hline \multicolumn{2}{c}{ Element 1 Totals (kg) } \\
\hline Element 1 Wet mass & $\mathbf{3 6 9 8}$ \\
Element 1 Dry mass & 2445 \\
Element 1 Inert mass (sans US TVC with growth) & $\mathbf{2 5 1 7}$ \\
\hline \hline
\end{tabular}




\section{B. Concept Drawing and Description}

The NEP KBOO S/C can be broken down into three main sections: the reactor and power conversion elements, reactor boom, and $\mathrm{S} / \mathrm{C}$ bus. Overall deployed dimensions can be seen in Figure 9.

The reactor and power conversion section of the NEP KBOO S/C contains the reactor, reactor shield, Stirling converters, and the power conversion radiator. These components all remain fixed in relation to one another during deployment of the $\mathrm{S} / \mathrm{C}$ and are mounted to a tapered box truss section. Upon deployment, the tapered box truss and all of the reactor and power conversion components are deployed away from the S/C bus by a telescoping boom. Deployment allows the reactor to have the desired separation distance from the bus electronics and allows all the deployed bus components to remain within the $11.7^{\circ}$ half-angle shield cone. The reactor and power conversion components can be seen in Figure 10 while Figure 11 shows how the NEP KBOO S/C components operate within the shield cone.

The telescoping reactor boom is comprised of three box trusses of equal length that stow within one another at launch providing sufficient stiffness for the launch loads and allow the $\mathrm{S} / \mathrm{C}$ to fit within the payload fairing. The length of each of the three box trusses composing the telescoping boom were driven by the need to have the reactor a certain distance away from the closest electronics contained on the bus. That distance is $12.66 \mathrm{~m}$ in this design. One end of the boom is mounted to the bus structure, while the other end is mounted to the tapered box truss containing the reactor and power conversion components. The shunt radiator is mounted to the box truss of the boom. A more detailed discussion on the design of the telescoping boom in the mechanical subsystems section.

The primary bus structure for the NEP KBOO S/C is comprised of a thrust-tube design that is $1.63 \mathrm{~m}$ in diameter and $2.65 \mathrm{~m}$ tall. The diameter of the bus structure allows the $\mathrm{S} / \mathrm{C}$ to interface directly to the DIVH 1666-5 PAF and allows the Xe tank to mount along the inside perimeter of the bus structure. There is a lower deck within the bus structure that provides mounting for the Electric Propulsion (EP) components, and an upper deck that provides mounting for all the internal subsystem electronics.

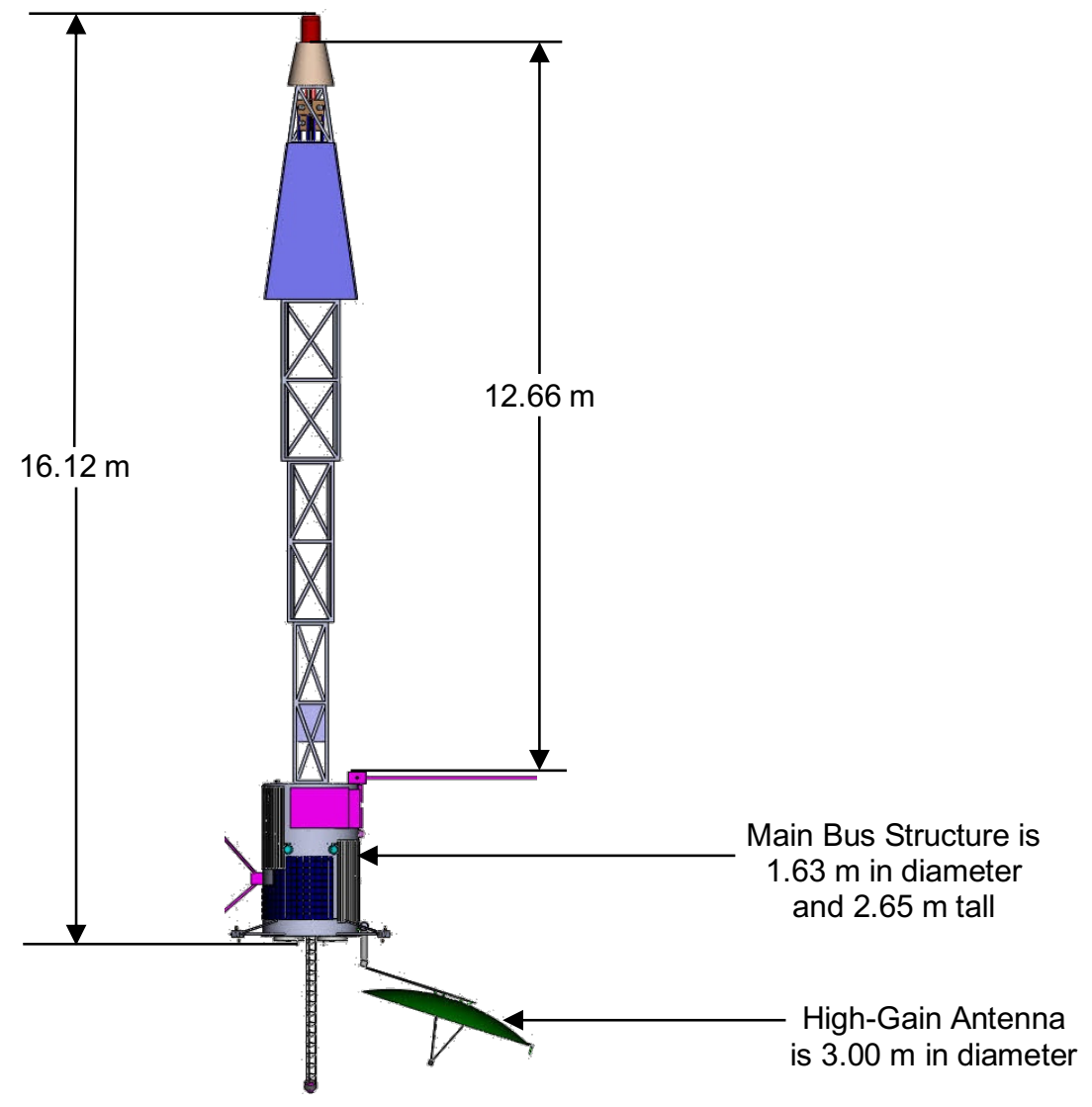

Figure 9. Primary sections of the NEP KBOO S/C. 


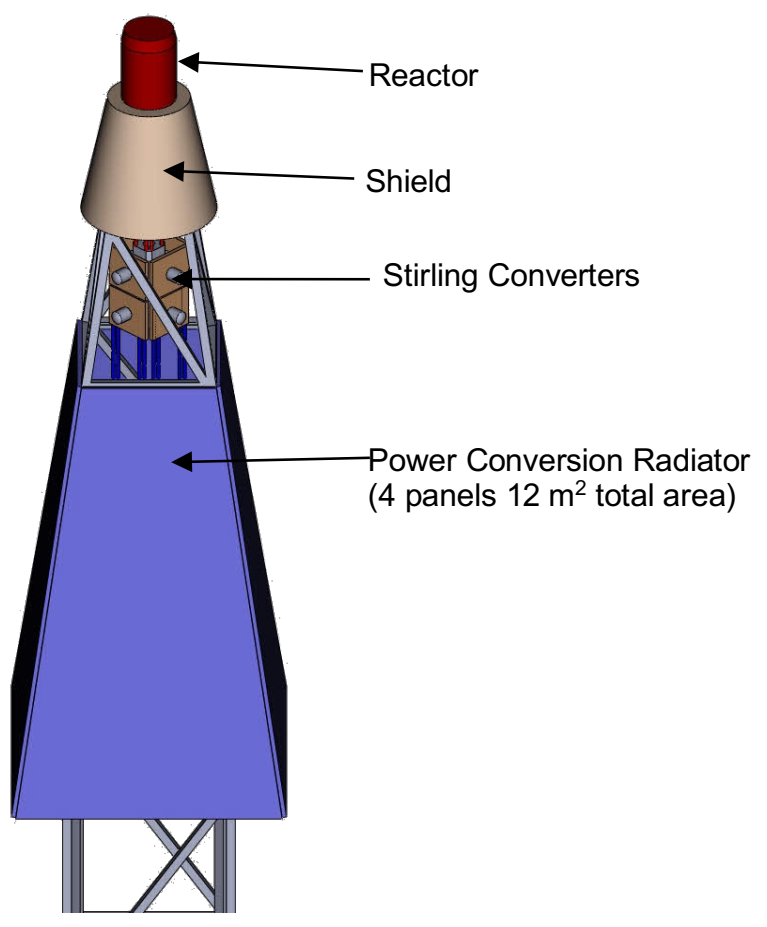

Figure 10. Reactor and power conversion components.
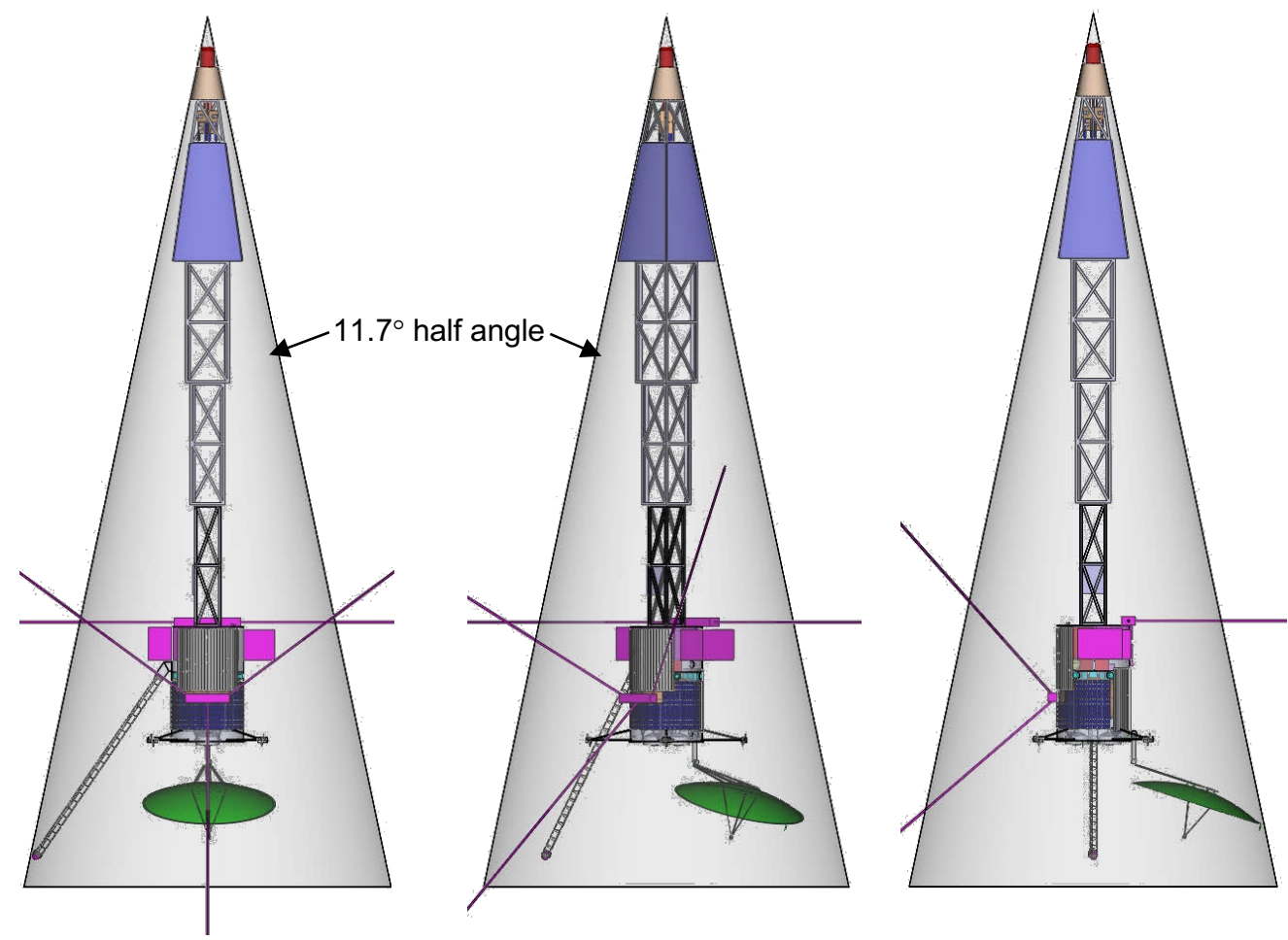

Figure 11. NEP KBOO S/C within the shield cone.

Those components located external to the bus structure include the radiators, start-up SA, communications antennas, star trackers, NEXT thrusters, RCS thrusters, and the suite of science sensors. While many of the science sensors are mounted on the outside of the bus structure, some of them are mounted within the bus structure while their sensors protrude from the bus structure. This was done to allow all the science to point in the same direction and to allow the $\mathrm{S} / \mathrm{C}$ to fit within the payload fairing. A more detailed discussion on the suite of science instruments contained 
on the NEP KBOO S/C can be found in elsewhere in this paper. Those components external to the S/C bus can be seen in Figure 12.

The radiator panels are mounted directly to the outside of the bus structure and are curved to fit the cylindrical shape of the bus. Due to the large total area required for heat rejection and the restricted surface area of the bus structure, the radiators were split into two individual panels. One panel is located directly below the suite of science sensors and extends down near the base of the bus, while the other is located on the opposite side $\left(180^{\circ}\right)$ and extends down from the top of the bus.

The SA used for deployment and reactor startup power is body mounted to the outside of the bus and is curved to fit on the cylindrical structure. In order to obtain the required array area of $3 \mathrm{~m}^{3}$, cutouts for other bus components were added to the array to allow the entire area to fit on the bus structure without any shadowing from other components. The SA wraps $230^{\circ}$ around the bus on the side opposite the suite of science sensors. A better image of the SA size, shape, and location can be seen in Figure 13.

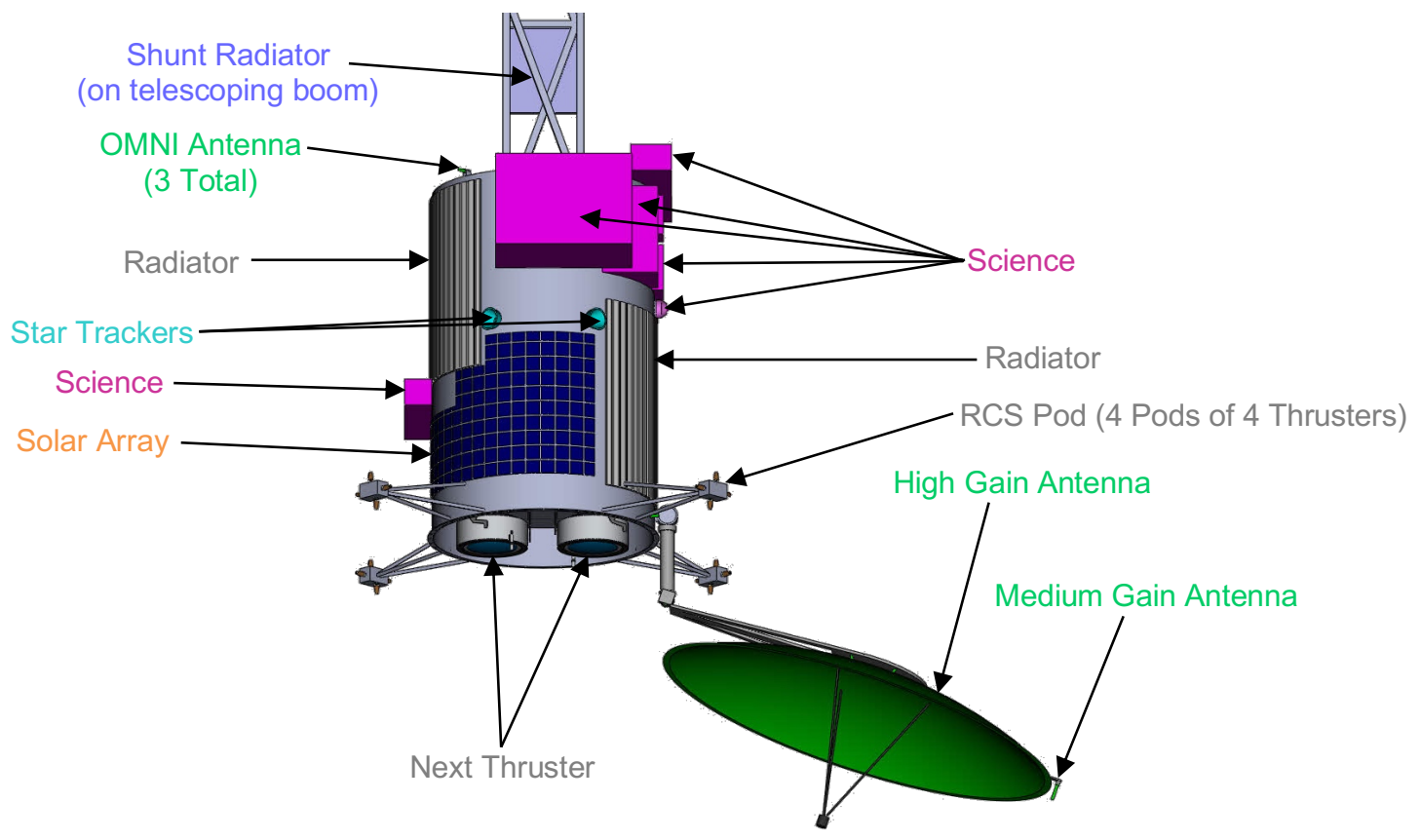

Figure 12. External bus components of the NEP KBOO S/C.

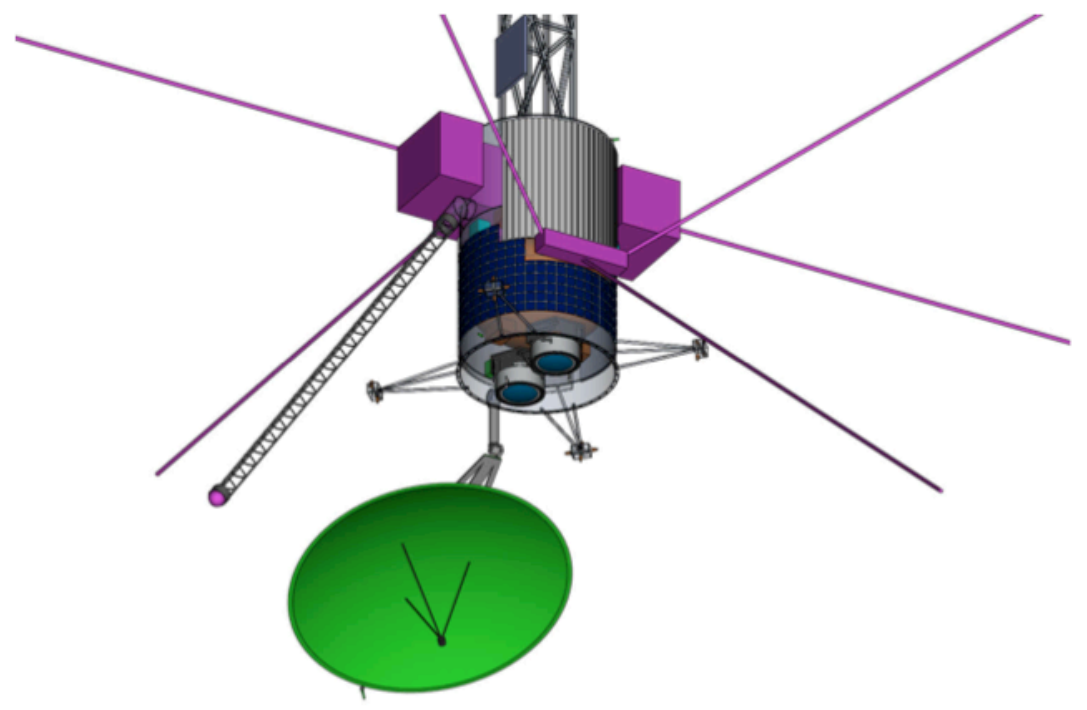

Figure 13. Isometric view of the NEP KBOO bus structure. 
There are $3 \mathrm{X}$-band dipole antennas located on the $\mathrm{S} / \mathrm{C}$ bus with each pointing out radially from the cylindrical structure and located $120^{\circ}$ from one another around the bus. In order to obtain the best field of view for the dipole antennas, one is mounted to the top of the bus structure while the other two are located near the aft end of the bus. The $3-\mathrm{m} \mathrm{X} / \mathrm{Ka}$-band high-gain antenna is located on the end of a 0.6-m long boom that extends beyond the aft end of the bus structure to provide an unobstructed field-of-view as well as allow a full range of motion when gimbaled. Mounted to the outside of the 3-m dish is the X-band medium-gain antenna. It is oriented to point in the same direction as the high-gain dish and both are pointed by a two-axis gimbal located at the end of the antenna boom.

The two star trackers, though mounted to the underside of the upper deck inside the bus structure, extend outside of the bus to obtain an unobstructed field-of-view. They are located between the two radiator panels and just above the body mounted SA. The star trackers are pointed perpendicular to one another and the centerline between them is perpendicular to the direction of the suite of science sensors.

The two NEXT EP thrusters and their gimbals are mounted to the underside of the lower deck of the bus structure. This location keeps all of the other $\mathrm{S} / \mathrm{C}$ components outside of the plume cone and allows for minimal gimbaling to ensure thrusting through the vehicle's center of gravity. While in some instances the high-gain antenna may be directly in the plume cone, the concept of operations ensures that the dish will be maneuvered outside of this cone when thrusting with the NEXT thrusters.

Finally, the RCS thrusters are contained within 4 pods of 4 thrusters each located on the end of a boom structure that extends radially from the bottom of the bus structure. These booms are equally spaced $\left(90^{\circ}\right)$ around the perimeter of the bus structure. The use of the booms allowed a larger moment arm for each of the thrusters when firing. Orientation of the thrusters within the pods allows for a full range of motion around the yaw, pitch, and roll axes with redundancy.

Those components contained completely inside the bus structure are the electrical power electronics, science electronics, communications electronics, reaction wheels and inertial measurement unit of the attitude determination and control subsystem, command and data handling electronics, RCS propellant tanks, Xe tank, and the direct drive units (DDU) and feed system for the EP thrusters. The internal layout of the NEP KBOO S/C can be seen in Figure 14.

All of the communications electronics are mounted to the inside wall of the bus structure near the top and opposite the suite of science sensors. The top face of the top deck within the bus structure provides the interface for all of the electrical power electronics, the science penetrator electronics, and the RCS propellant tanks. The bottom face of the top deck provides the interface for the reaction wheels, IMU, and the enclosure for the command and data handling electronics. Below the top deck is the Xe propellant tank which is mounted to the inside wall of the bus structure via a set of tabs around the perimeter of the tank. The bottom deck is located just below the Xe tank and provides the interface for the two DDUs and Xe feed system.

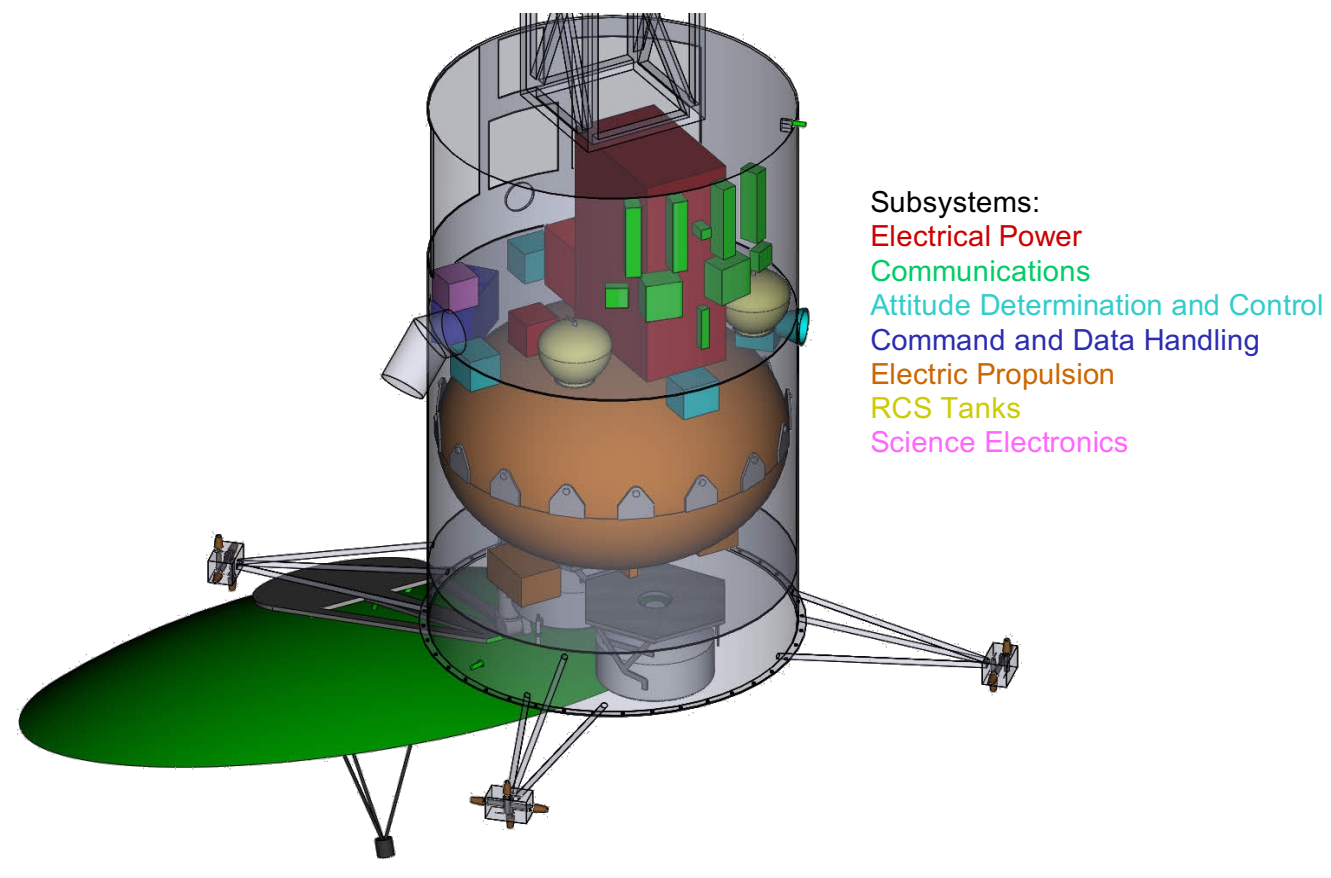

Figure 14. Internal Bus Components. 


\section{III.SUBSYSTEM BREAKDOWN}

\section{A. Science Package}

The Science Package for the NEP KBOO study is assumed to be the same suite of instruments that were defined in the REP KBOO Study (CD-2009-32) and are replicated for reference below.

- Observe KBO for $1 \mathrm{yr}$

- Utilize high power (radar)

- In-situ investigation of surface using penetrators

- Science inputs

- Mass: $130 \mathrm{~kg}$ with contingency

- Power: $225 \mathrm{~W}$

- Data volume: worst case of $474 \mathrm{~Gb}$ for full mapping in 1 month

- Instrument suite

- Data volume $\sim 474 \mathrm{~Gb}$ needs and additional $7 \%$ overhead and $30 \%$ contingency

- Full science acquisition period $=90$ days over $1 \mathrm{yr}$

- Pointing control and stability $=0.030^{\circ}$

- Pointing knowledge $<0.002^{\circ}$

\section{Science Assumptions}

The science package for the NEP KBOO was book kept in the MEL as a black box that represented the suite of instruments in the original REP KBOO design study. Mass, power, and volume were assumed to be the same from REP KBOO. The science instruments included Visual, Near/Mid, Charged Particle, Far IR, Neutral/Ion Mass and Near UV/V Spectrometers in addition to magnetometers and a radar.

2. Science Design and MEL

Table 6. Science NEP KBOO MEL

\begin{tabular}{|c|c|c|c|c|c|c|}
\hline $\begin{array}{c}\text { Description } \\
\text { NEP KBOO CD-2012-77 }\end{array}$ & QTY & $\begin{array}{c}\text { Unit Mass } \\
(\mathrm{kg})\end{array}$ & $\begin{array}{c}\text { Basic Mass } \\
(\mathrm{kg})\end{array}$ & $\begin{array}{c}\text { Growth } \\
(\%)\end{array}$ & $\begin{array}{c}\text { Growth } \\
\text { (kg) }\end{array}$ & $\begin{array}{c}\text { Total Mass } \\
(\mathbf{k g}) \\
\end{array}$ \\
\hline NEP Kuiper Belt Object Orbiter (KBOO) & & & 2962.19 & $6.6 \%$ & 195.84 & 3158.03 \\
\hline NEP KBOO Vehicle & & & 2962.19 & $6.6 \%$ & 195.84 & 3158.03 \\
\hline Science & & & 100.00 & $0.0 \%$ & 0.00 & 100.00 \\
\hline Science package group one & & & 100.00 & $0.0 \%$ & 0.00 & 100.00 \\
\hline Black Box Science Package & 1 & 100.00 & 100.00 & $0.0 \%$ & 0.00 & 100.00 \\
\hline
\end{tabular}

\section{B. Communications}

The communications back from the $\mathrm{KBO}$ are challenging due to its extreme distance of $38 \mathrm{AU}$ and the significant amount of data desired. From the JPL presentation on the mission, JREPS Neptune System Explorer, the suite of instruments that might be on the KBOO mission a data rate for each instrument is given but not a time duration of operations. Table 7 shows the suite of instruments and their required data rate.

Table 7. Instrument Data Rates

\begin{tabular}{lclclc}
\hline \hline \multicolumn{1}{c}{ Instrument } & $\begin{array}{c}\text { Data rate } \\
\text { (kbps) }\end{array}$ & \multicolumn{1}{c}{ Instrument } & $\begin{array}{c}\text { Data rate } \\
\text { (kbps) }\end{array}$ & $\begin{array}{c}\text { Instrument } \\
\text { Far IR spectrometer }\end{array}$ & $\begin{array}{c}\text { Data rate } \\
\text { (kbps) }\end{array}$ \\
\hline Visual spectrometer & 350 & Near/Mid IR spectrometer & 180 & Far & 6 \\
Microwave Radiometer & NA & Near UV/Vis Spectrometer & 32 & Radar & 75 \\
Charged particle spectrometer & 4 & Neutral/Ion Mass spectrometer & 2 & --------- & -- \\
\hline \hline
\end{tabular}

1. Communications Requirements

For the communication from the KBO back to Earth a maximum distance between the S/C and the Earth of $38 \mathrm{AU}$ with a maximum data rate of $40 \mathrm{kbps}$ from a $3 \mathrm{~m}$ diameter Ka-band antenna to a $70 \mathrm{~m}$ antenna on Earth was assumed. The required transmit power was determined from a link budget (Figure 16) and assumed 50\% efficiency for the high power amplifier. The receiver is assumed to require $5 \mathrm{~W}$ of power and the modulator and encoder power need is $10 \mathrm{~W}$.

2. Communications Assumptions

- The communication properties 
- Distance is $38 \mathrm{AU}$

- Frequency is $32 \mathrm{GHz}$

- Satellite antenna size is $3 \mathrm{~m}$

- Ground terminal is assumed to be an equivalent $70 \mathrm{~m}$ antenna system upgraded to $32 \mathrm{GHz}$ with the same receiver noise temperature as the current $34 \mathrm{~m}$ antenna system at $32 \mathrm{GHz}$.

- $\quad$ LPDC coding with Eb/N0 of $2.2 \mathrm{~dB}$

- $\quad$ RF power out of the high power amplifier is $200 \mathrm{~W}$

- No rain fade

\section{Communications Design and MEL}

The communication system consists of $32 \mathrm{GHz} \mathrm{Ka-band} \mathrm{transmit} \mathrm{only} \mathrm{system} \mathrm{and} \mathrm{a} \mathrm{two-way} \mathrm{X-band}$ communication system. The communication system is single fault tolerant except for the antennas and diplexers. There are one dual X-band and one Ka-band $3 \mathrm{~m}$ gimbaled antenna, one medium gain ( $8 \mathrm{dBi}$ ) X-band antenna and three Xband dipole antennas (gain $1.5 \mathrm{dBi}$ ) on the $\mathrm{S} / \mathrm{C}$. Ranging and Doppler shift measurements can be done using either the $\mathrm{X}$-band or Ka-band system.

The X-band communication system is used while the S/C is thrusting for telemetry, health, status and commands, while the Ka-band communication is only used for science data return, ranging and Doppler shift measurements. The Ka-band communication when used for ranging and Doppler shift measurements uses a 15 W SSPA while when the $\mathrm{S} / \mathrm{C}$ is not thrusting it uses one $200 \mathrm{WRF}$ TWTA for higher data rate communications.

\section{Communications Trades}

A link budget for a 200 WRF TWTA system is shown in Figure 16. The maximum data rate is $67.6 \mathrm{kbps}$.

Table 8 shows the master power list for the Ka-band communications system.

Table 9 shows the MEL for the entire communications and tracking subsystem.

\section{Communications Analytical Methods}

The communication system is sized for a link distance of $37 \mathrm{AU}$. LPDC coding is assumed. The required EB/N0 is $2.2 \mathrm{~dB}$ for a BER of $10 \times 10^{-4}$. The receive antenna on Earth is assumed to be an upgrade of the current $70 \mathrm{~m}$ dish or its equivalent at $32 \mathrm{GHz}$. The Earth's antenna gain to noise temperature is assumed to be $64.9 \mathrm{dBi} / \mathrm{K}$. The $200 \mathrm{~W}$ RF power system provides a data rate of $67.6 \mathrm{kbps}$; the link closes with a $3.5 \mathrm{~dB}$ link margin. For X-band there are two modes. One mode uses the dual X-band and Ka-band antenna. A data rate of 1600 bps through the antenna at X-band to the $70 \mathrm{~m}$ antenna can be supported. For the medium X-band antenna the data rate is 4 bps at the maximum range. The medium gain antenna is assumed to be mounted on the high gain antenna so both are pointed to Earth at the same time. 


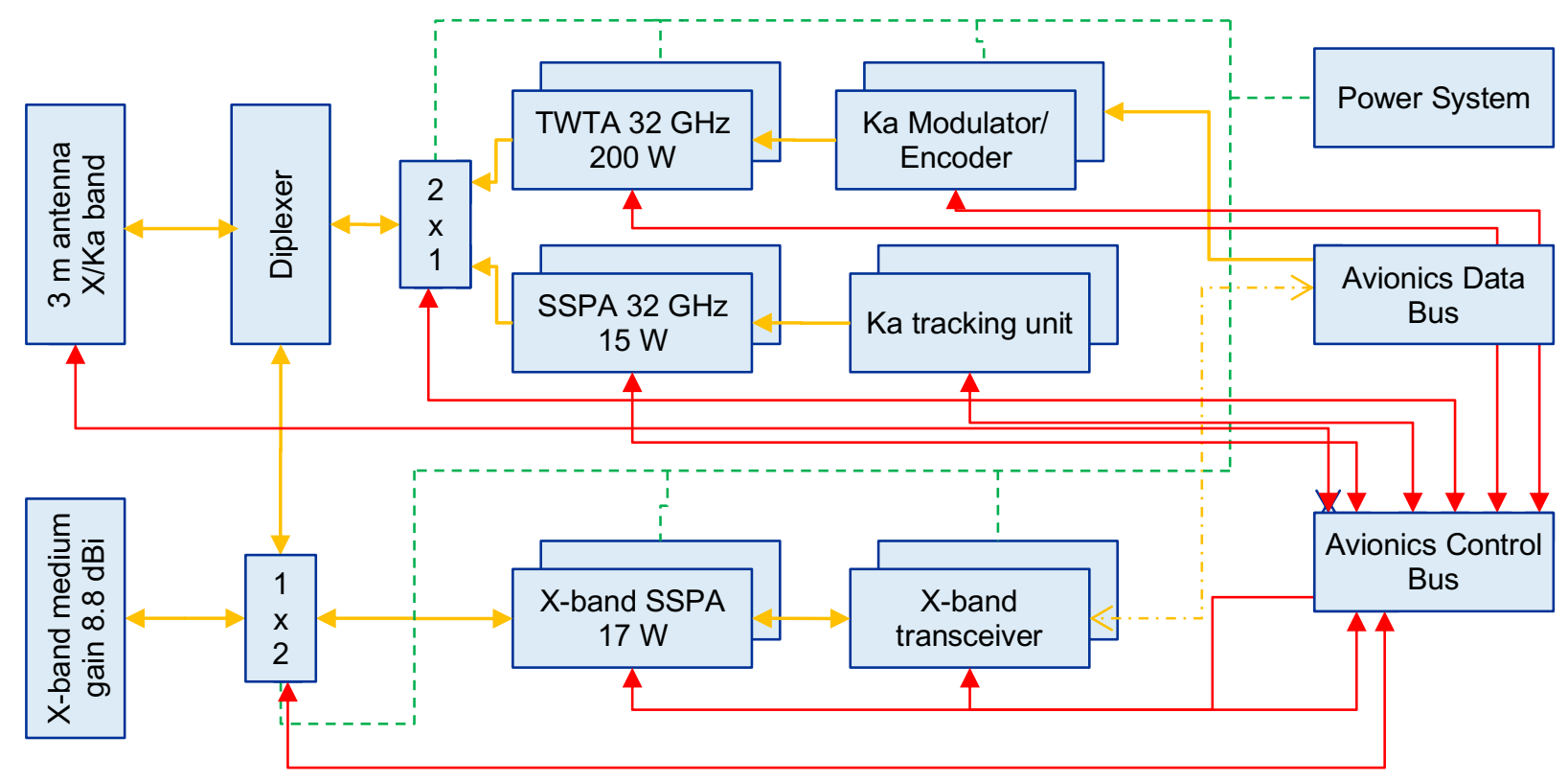

Figure 15. Schematic of RF Systems

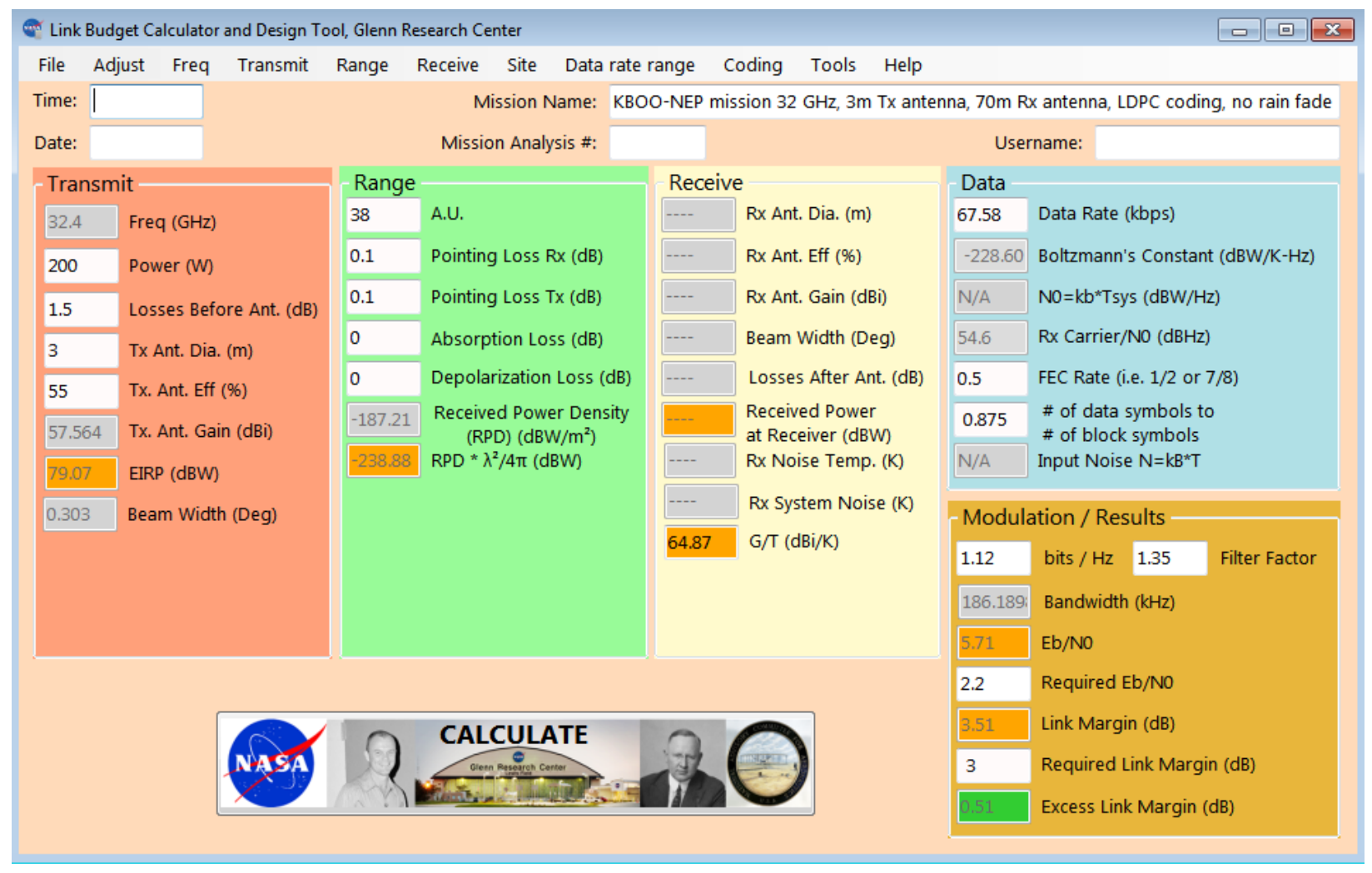

Figure 16. Communications Link Budget 
Table 8. Communications Ka-Band Master Power List

\begin{tabular}{lccc}
\hline \hline & \multicolumn{3}{c}{ 200 W System } \\
& Modes (W) \\
\hline Ka-band component & Off & Standby & On \\
Antenna (3.0 m diameter) & 0 & 0 & 0 \\
Deep space transponder (SDST) & 0 & 12.5 & 28.3 \\
Waveguide and cables & 0 & 0 & 0 \\
Antenna Gimbals & 0 & 17 & 17 \\
Traveling Wave Tube Assembly (TWTA) & 0 & 14 & 400 \\
Electric Power Conditioner (EPC) & 0 & 0 & 0 \\
Switches/Power Combiners & 0 & 0 & 0 \\
X-band Medium Gain Antenna & 0 & 0 & 0 \\
X-band Diplexer & 0 & 0 & .4 \\
X-band SSPA ( 15 W) & 0 & 0 & 60 \\
Grand Total Power (WDC) & 0 & 43.5 & 509.3 \\
\hline \hline
\end{tabular}

Table 9. NEP KBOO MEL Communications \& Tracking Subsystem

\begin{tabular}{|c|c|c|c|c|c|c|}
\hline $\begin{array}{c}\text { Description } \\
\text { NEP KBOO CD-2012-77 }\end{array}$ & QTY & $\begin{array}{c}\text { Unit Mass } \\
(\mathrm{kg})\end{array}$ & $\begin{array}{c}\text { Basic Mass } \\
(\mathrm{kg})\end{array}$ & $\begin{array}{c}\text { Growth } \\
(\%)\end{array}$ & $\begin{array}{c}\text { Growth } \\
\text { (kg) }\end{array}$ & $\begin{array}{c}\text { Total Mass } \\
(\mathrm{kg})\end{array}$ \\
\hline NEP Kuiper Belt Object Orbiter (KBOO) & & & 2962.19 & $6.6 \%$ & 195.84 & 3158.03 \\
\hline NEP KBOO Vehicle & & & 2962.19 & $6.6 \%$ & 195.84 & 3158.03 \\
\hline Communications and Tracking & & & 52.90 & $21.5 \%$ & 11.36 & 64.26 \\
\hline X Band System & & & 19.60 & $12.3 \%$ & 2.42 & 22.02 \\
\hline Deep Space Transponder X/X/Ka & 2 & 3.20 & 6.40 & $5.0 \%$ & 0.32 & 6.72 \\
\hline Gimbal & 1 & 5.30 & 5.30 & $10.0 \%$ & 0.53 & 5.83 \\
\hline Cables & 0 & 0.00 & 0.00 & $0.0 \%$ & 0.00 & 0.00 \\
\hline X-band SSPA & 2 & 1.50 & 3.00 & $30.0 \%$ & 0.90 & 3.90 \\
\hline Gimbal Controller & 2 & 2.00 & 4.00 & $10.0 \%$ & 0.40 & 4.40 \\
\hline Gimbal arm & 1 & 0.50 & 0.50 & $30.0 \%$ & 0.15 & 0.65 \\
\hline X-band Diplexer & 1 & 0.40 & 0.40 & $30.0 \%$ & 0.12 & 0.52 \\
\hline Ka Band DTE Link & & & 9.10 & $18.5 \%$ & 1.68 & 10.78 \\
\hline UST, No Relay, Dual Band & 0 & 0.00 & 0.00 & $0.0 \%$ & 0.00 & 0.00 \\
\hline Ka-band TWTA RF $=140-200 \mathrm{~W}$ & 2 & 1.50 & 3.00 & $10.0 \%$ & 0.30 & 3.30 \\
\hline $\mathrm{EPC}$ & 2 & 1.50 & 3.00 & $15.0 \%$ & 0.45 & 3.45 \\
\hline Switches and Combiners & 1 & 0.30 & 0.30 & $30.0 \%$ & 0.09 & 0.39 \\
\hline Cables and waveguide & 1 & 2.80 & 2.80 & $30.0 \%$ & 0.84 & 3.64 \\
\hline Comm Avionics & & & 0.00 & 0 & 0.00 & 0.00 \\
\hline Antennas & & & 24.20 & $30.0 \%$ & 7.26 & 31.46 \\
\hline $\mathrm{X} /$ Ka-high gain antenna $3.0 \mathrm{~m}$ diam. parabolic & 1 & 20.00 & 20.00 & $30.0 \%$ & 6.00 & 26.00 \\
\hline $\mathrm{X}$-medium gain antenna & 1 & 1.20 & 1.20 & $30.0 \%$ & 0.36 & 1.56 \\
\hline Omni-X-band & 3 & 1.00 & 3.00 & $30.0 \%$ & 0.90 & 3.90 \\
\hline
\end{tabular}

\section{Command and Data Handling (C\&DH)}

The main purpose of the C\&DH system is collecting and distributing nonflight-critical sensor data from the instrumentation throughout the mission and storing it in local memory via high-speed data buses. AD\&C, propulsion, and thermal control requirements require controlling valves and gimbals, as well as sensing pressure and temperature 
transducers. All telemetry acquisition and processing of data is followed by forwarding the data to the communication subsystem for transmission to Earth.

\section{1. $C \& D H$ Requirements}

The design requirements for the $\mathrm{C} \& \mathrm{DH}$ system are as follows:

- Avionics components and parts shall be Class S, per MIL-STD-883B.

- Avionics shall be one fault tolerant using cold spares.

- Data storage unit shall provide at least $100 \mathrm{~GB}$ of onboard permanent solid-state memory.

- Avionics shall be ground-bonded and surge-protected to resist on-pad lightning damage.

- Avionics shall be designed to withstand the on-orbit ionizing and non-ionizing radiation environments dictated by the mission profile. It is important to avoid over-specifying the rad-tolerance levels to minimize cost for parts and testing. Due to the flight profile intended for this mission, radiation tolerance is planned to be $100 \mathrm{krad}$ for reactor particles and a total of $110 \mathrm{krad}$ including remaining external sources.

\section{C\&DH Assumptions}

The following design assumptions are based on the mission requirements:

- Implemented with rad-tolerant microcontrollers, Field-Programmable Gate Arrays (FPGAs), and data storage using solid-state random access memory (RAM) and Flash memory. The RAD750 processor is an example of a modern rad-tolerant microcontroller.

- Avionics spare circuitry for fault tolerance is implemented as cold spares in order to minimize power consumption.

- Hardware design heritage is based on previous $\mathrm{S} / \mathrm{C}$ and lessons learned.

- Sensor estimate is based on a preliminary assumption of number of channels for input and output.

3. $C \& D H$ Design and $M E L$

The C\&DH system consists of RAD750 or LEON3-class processor boards containing various hardware and software mechanisms such as timeouts and watchdog circuitry to provide for single fault tolerance. Each processor board includes an FPGA-embedded core built with a main processor such as the RAD750 series, capable of supporting C\&DH functions, a $100 \mathrm{~GB}$ solid-state memory card, as well as communications and payload interface cards. The primary processor is capable of autonomous failover to a redundant cold spare unit if a fault is detected.

Depending on choice of processor, flight computers will use a real-time operating system such as VxWorks or Green Hills Integrity. To support all mission phases, the number of source lines of code (SLOC) has been estimated to be approximately 200,000 SLOCs. However, this estimate and implied development cost should be tempered with the understanding that recent developments in autocoder technologies that generate known good instruction loads will become a design standard.

The following list is comprised of the main avionics components and their quantities, as input to the MEL shown in Table 10:

- Main computers (one main computer and one redundant cold spare)

- Data acquisition channels (including redundant paths for single-fault tolerance)

- Redundant solid-state memory

- Instrumentation (including approximately 40 sensors, mass of 6 oz. each, power requirement of $50 \mathrm{~mW}$ each)

Table 10. C\&DH MEL

\begin{tabular}{|c|c|c|c|c|c|c|}
\hline $\begin{array}{c}\text { Description } \\
\text { NEP KBOO CD-2012-77 }\end{array}$ & Q QTY & $\begin{array}{c}\text { Unit Mass } \\
(\mathrm{kg})\end{array}$ & $\begin{array}{c}\text { Basic Mass } \\
(\mathrm{kg})\end{array}$ & $\begin{array}{c}\text { Growth } \\
(\%)\end{array}$ & $\begin{array}{c}\text { Growth } \\
(\mathrm{kg})\end{array}$ & $\begin{array}{c}\text { Total Mass } \\
(\mathbf{k g})\end{array}$ \\
\hline NEP Kuiper Belt Object Orbiter (KBOO) & & & 2962.19 & $6.6 \%$ & 195.84 & 3158.03 \\
\hline NEP KBOO Vehicle & & & 2962.19 & $6.6 \%$ & 195.84 & 3158.03 \\
\hline Command \& Data Handling & & & 36.21 & $24.2 \%$ & 8.76 & 44.97 \\
\hline C\&DH Hardware & & & 32.60 & $23.6 \%$ & 7.68 & 40.28 \\
\hline FPGA-based IP for 750-class processor & 2 & 1.00 & 2.00 & $10.0 \%$ & 0.20 & 2.20 \\
\hline Command and Telemetry Computer & 0 & 0.00 & 0.00 & $0.0 \%$ & 0.00 & 0.00 \\
\hline Data Interface Unit & 2 & 1.00 & 2.00 & $20.0 \%$ & 0.40 & 2.40 \\
\hline Time Generation Unit & 2 & 1.00 & 2.00 & $10.0 \%$ & 0.20 & 2.20 \\
\hline $100 \mathrm{~GB}$ solid state memory & 2 & 4.00 & 8.00 & $30.0 \%$ & 2.40 & 10.40 \\
\hline Command and Control Harness (data) & 1 & 5.00 & 5.00 & $20.0 \%$ & 1.00 & 6.00 \\
\hline
\end{tabular}




\begin{tabular}{|c|c|c|c|c|c|c|}
\hline cPCI enclosure w/ power supply & 1 & 5.00 & 5.00 & $30.0 \%$ & 1.50 & 6.50 \\
\hline Ultra-Oscillator and Atomic Clock Module & 2 & 0.30 & 0.60 & $30.0 \%$ & 0.18 & 0.78 \\
\hline Gimbal Control Card & 2 & 2.00 & 4.00 & $30.0 \%$ & 1.20 & 5.20 \\
\hline Feed System Driver Card & 2 & 1.00 & 2.00 & $30.0 \%$ & 0.60 & 2.60 \\
\hline Thrust Valve Card & 2 & 1.00 & 2.00 & $0.0 \%$ & 0.00 & 2.00 \\
\hline Pyro Card & 0 & 0.30 & 0.00 & $0.0 \%$ & 0.00 & 0.00 \\
\hline SLOCS & 200000 & 0.00 & 0.00 & $0.0 \%$ & 0.00 & 0.00 \\
\hline Instrumentation \& Wiring & & & 3.61 & $30.0 \%$ & 1.08 & 4.69 \\
\hline 48 channel AD/DA/SDI card & 2 & 1.13 & 2.26 & $30.0 \%$ & 0.68 & 2.94 \\
\hline Data Cabling & 2 & 0.00 & 0.00 & $25.0 \%$ & 0.00 & 0.00 \\
\hline 48 channel SDO card & 1 & 1.35 & 1.35 & $30.0 \%$ & 0.41 & 1.76 \\
\hline
\end{tabular}

Note: As shown in the MEL, in the Lander, there are two 48-channel analog-to-digital (ADC) and digital-to-analog (DAC) and simple digital interface (SDI) cards and one 48-channel simple data output (SDO) card, giving 144 channels of input/output, not including any serial data bus input/output, all used to estimate worst-case mass and power.

- Spacecraft cabling (per Monte Carlo simulation):

- Instrumentation wiring 20-24 American Wire Gauge Tefzel (exclusive of high currents Power system conductors)

\section{Flight Computers and Software}

The flight computers and software shall have the following capabilities:

- Load, initialization, executive functions, and utilities executed by the processors

- Flight computer board redundancy management

- Data acquisition and control

- Command and telemetry processing via RS-422 or SERDES

- Health monitoring and management

- Power management, control, and distribution

- AD\&C calculations

- Ephemeris calculations for available data communications with Earth

- Event sequence management

- Fault detection, diagnostics, and recovery

5. Data Acquisition System

The main purpose of the data acquisition system is collecting and distributing non-flight-critical sensor data from the instrumentation throughout the mission and storing it on mass memory via high-speed data buses.

\section{C\&DH Analytical Methods}

As a matter of common practice, the design of a new S/C's C\&DH system is often based on one that is proven effective on another $\mathrm{S} / \mathrm{C}$, and that requires minor or no modifications for the mission currently under development. This C\&DH system is based on previous S/C, such as Dawn, New Horizons, and Extrasolar Planet Observation (EPOXI).

\section{Attitude Determination and Control (AD\&C)}

The AD\&C system both senses and maintains the $\mathrm{S} / \mathrm{C}$ attitude knowledge and then controls the attitude during mission. Spacecraft tracking (location) is provided by the communications system.

\section{AD\&C Requirements}

The AD\&C subsystem is required perform the following functions:

- Provide attitude determination and control from LV separation to the end of the mission

- Star 63F burn

- EP Thrusting

- Coast

- KBO Orbit Insertion

- Science phase in orbit around the KBO

- $\quad$ Pointing accuracy $=0.03^{\circ}$ 


\section{AD\&C Design}

The AD\&C design is dual mode stabilized, being 3-axis controlled during the STAR 63F burn, EP thrusting periods, $\mathrm{KBO}$ orbit insertion as well as the science phase, and spin stabilized during interplanetary coasts. A top level summary of the hardware for the design is as follows:

- TVC system added to STAR 63F for pitch/yaw control during burn

- 2 Selex Galileo Avionica Star Trackers with New Horizons heritage

- Slightly modified version of the off the shelf A-STR

- Software modifications were made to improve attitude determination accuracy while the S/C was spin stabilized

- 1 Internally redundant Northrop Grumman SIRU

- 6 Sun Sensors with New Horizons heritage

- 4 Valley Forge Composite Technologies T-Rex Reaction Wheels

- $75 \mathrm{Nms}$ of momentum storage each

Attitude is estimated during all phases by the sun sensors and star trackers, which are used to update the estimated attitude in the IMU.

Pitch and yaw control during the STAR 63F burn is provided by the addition of a TVC system to the STAR 63F. The Star 63 is not considered part of the S/C design but is instead considered part of the LV stack. Roll control during the STAR 63F burn is provided by the ACS thrusters.

After jettisoning the STAR 63F solid motor, the S/C is stabilized by one of two methods depending on the phase of the mission. The $\mathrm{S} / \mathrm{C}$ is 3-axis stabilized during all $\mathrm{EP}$ thrusting and science periods, with the long interplanetary coast being spin stabilized. Pitch and yaw control are provided by the NEXT engine during EP thrusting periods and since only 1 NEXT thruster operates at a time, roll control is provided by the reaction wheels. Momentum about the roll axis is dumped with the ACS thrusters when the wheels reach saturation. During coast periods the S/C is spun up/down to/from $5 \mathrm{rpm}$ by the ACS thrusters. Precession of the spin axis is also provided by the ACS thrusters during coast periods. During the science phase, reaction wheels provide 3-axis stabilization. The AD\&C MEL can be seen in Table 11.

\section{3. $A D \& C M E L$ and Mission $\triangle V$ Summary}

A summary of the mission $\Delta V$ 's can be seen in Table 2 .

- Total Main $\Delta \mathrm{V}$ of $15.4 \mathrm{~km} / \mathrm{s}$

- Propellant numbers from table represent required "useable" propellant

- Additional percentage of useable propellant carried as margin and included in vehicle inert mass

- $5 \%$ of useable for main propellant

- $10 \%$ of useable for ACS propellant

- Propulsion $\mathrm{I}_{\mathrm{sp}}$

- $\quad$ Main $=4188 \mathrm{~s}$

- $\mathrm{ACS}=229 \mathrm{~s}$

Table 11. AD\&C MEL

\begin{tabular}{|c|c|c|c|c|c|c|}
\hline $\begin{array}{c}\text { Description } \\
\text { NEP KBOO CD-2012-77 }\end{array}$ & QTY & $\begin{array}{c}\text { Unit Mass } \\
(\mathrm{kg})\end{array}$ & $\begin{array}{c}\text { Basic Mass } \\
(\mathrm{kg})\end{array}$ & $\begin{array}{c}\text { Growth } \\
(\%)\end{array}$ & $\begin{array}{c}\text { Growth } \\
\text { (kg) }\end{array}$ & $\begin{array}{c}\text { Total Mass } \\
(\mathbf{k g}) \\
\end{array}$ \\
\hline NEP Kuiper Belt Object Orbiter (KBOO) & & & 2962.19 & $6.6 \%$ & 195.84 & 3158.03 \\
\hline NEP KBOO Vehicle & & & 2962.19 & $6.6 \%$ & 195.84 & 3158.03 \\
\hline Attitude Determination and Control & & & 25.48 & $5.0 \%$ & 1.27 & 26.75 \\
\hline Guidance, Navigation, \& Control & & & 25.48 & $5.0 \%$ & 1.27 & 26.75 \\
\hline Inertial Measurement Units & 1 & 6.90 & 6.90 & $5.0 \%$ & 0.35 & 7.25 \\
\hline Sun Sensors & 6 & 0.01 & 0.06 & $5.0 \%$ & 0.00 & 0.06 \\
\hline Star Tracker & 2 & 3.10 & 6.20 & $5.0 \%$ & 0.31 & 6.51 \\
\hline Reaction Wheels & 4 & 3.08 & 12.32 & $5.0 \%$ & 0.62 & 12.94 \\
\hline
\end{tabular}

4. AD\&C Analytical Methods

The methods used to design the AD\&C system involve using a mix of published values, empirical data, and analytical tools. Published values and empirical data are used wherever possible, with analytical tools being employed as necessary. Empirical data is used to aid in the mass and size estimation of similar systems when published values 
are not available. Numerous analytical tools are used in the analysis, as well as custom tools developed from basic physical relationships.

The Star 63 is not considered part of the S/C design but is instead considered part of the LV stack. An attempt was made to estimate the mass of the TVC system that would be required to be added to the STAR 63F by linearly scaling the mass of the TVC system on the STAR 48V by the thrust level of the two engines. The resulting estimate of the TVC system for the STAR $63 \mathrm{~F}$ was $\sim 44 \mathrm{~kg}$.

Disturbance Torques: A summary of the disturbance torques can be seen in While the STAR 63F was not part of this design, the roll disturbance torque induce by the motor does have to be offset by the ACS thrusters. The roll disturbance torque from the solid motor was assumed to be $\sim 12 \mathrm{Nm}$ for this design. This assumption was based off of the disturbance torque of the Hercules X-259 motor reported by Knauber, which has a similar thrust level to the STAR $63 \mathrm{~F}$. Assuming a roll disturbance torque of $12 \mathrm{Nm}$ from the solid motor, it was estimated that less than $1 \mathrm{~kg}$ of ACS propellant would be required to offset it.

The magnitude of the swirl torque from the NEXT engine was assumed to $1.5 \times 10^{-4} \mathrm{Nm}$ and is generated about the thrust axis. This torque cannot be offset by the NEXT thruster since only 1 thruster operates at a time. This torque is instead absorbed by the reaction wheels and the wheels are dumped by the ACS thrusters when they reach saturation. It was estimated that the swirl torque saturates the reaction wheels in approximately $\sim 5$ days of thrusting.

Table 12.

While the STAR 63F was not part of this design, the roll disturbance torque induce by the motor does have to be offset by the ACS thrusters. The roll disturbance torque from the solid motor was assumed to be $\sim 12 \mathrm{Nm}$ for this design. This assumption was based off of the disturbance torque of the Hercules X-259 motor reported by Knauber, ${ }^{5}$ which has a similar thrust level to the STAR 63F. Assuming a roll disturbance torque of $12 \mathrm{Nm}$ from the solid motor, it was estimated that less than $1 \mathrm{~kg}$ of ACS propellant would be required to offset it.

The magnitude of the swirl torque from the NEXT engine was assumed to $1.5 \times 10^{-4} \mathrm{Nm}$ and is generated about the thrust axis. This torque cannot be offset by the NEXT thruster since only 1 thruster operates at a time. This torque is instead absorbed by the reaction wheels and the wheels are dumped by the ACS thrusters when they reach saturation. It was estimated that the swirl torque saturates the reaction wheels in approximately $\sim 5$ days of thrusting.

Table 12. Summary of Disturbance Torques

\begin{tabular}{lc}
\hline \hline \multicolumn{1}{c}{ Disturbance Torque } & Value $(\mathbf{N m})$ \\
\hline STAR 63F Roll Torque & 12 \\
NEXT Swirl Torque & $1.5 \times 10^{-4}$ \\
Gravity Gradient & $7 \times 10^{-7}$ \\
\hline \hline
\end{tabular}

The gravity gradient torque while in orbit around the $\mathrm{KBO}$ was estimated to be $\sim 7 \times 10^{-7} \mathrm{Nm}$, assuming an altitude of $10 \mathrm{~km}$ and a vehicle orientation of $45^{\circ}$ off the local vertical.

\section{E. Electrical Power System}

\section{Power Requirements}

Table 3 shows the power requirements for the $\mathrm{KBOO}$ mission. The peak power of $7.5 \mathrm{~kW}_{\mathrm{e}}$ occurs during thrusting out to the Kuiper belt with $6.9 \mathrm{~kW}_{\mathrm{e}}$ going to the EP system. Thrust time is $6.1 \mathrm{yr}$ with $9.88 \mathrm{yr}$ of coast to reach and orbit a Kuiper belt object. Science mission duration at the $\mathrm{KBOO}$ is $1 \mathrm{yr}$ with a total power output of $1 \mathrm{~kW}$. Launch and prelaunch power output is $168 \mathrm{~W}$ for $125 \mathrm{~min}$.

\section{Power Assumptions}

It was assumed that a Kilopower class reactor would be available for this mission. ${ }^{2}$ Kilopower is a joint NASA/DOE project to investigate development of reactors (power levels 1-10 kWe) that can be integrated with a wide range of power conversion technologies. In 2018 the $1 \mathrm{~kW}_{\mathrm{e}}$ DC variant of the Kilopower design was successfully tested at a DOE site in Nevada. ${ }^{3}$ This reactor was coupled to 8 Stirling convertors ( 2 convertors, 6 simulators) which convert the reactor generated heat to electrical power. It was assumed that 8 Stirling convertors (only 6 were required to operate and provide full power) would be integrated with the reactor and heat would be rejected via a heat pipe radiator. Additionally, it was assumed that a new $1.5 \mathrm{~kW}_{\mathrm{e}}$ class of Stirling convertor would be designed and developed based upon the SunPower free piston Stirling convertor used in the Advanced Stirling Convertor (ASC). Finally, a battery/SA system would be used for reactor startup. 


\section{Power Design and MEL}

Figure 18 shows how four of the eight Stirling convertors are attached to both the reactor and the radiator. Total reactor thermal power is $31 \mathrm{~kW}_{\text {th }}$ with an overall conversion efficiency of $25 \%$ to provide $8 \mathrm{~kW}_{\mathrm{e}}$ to the $\mathrm{S} / \mathrm{C}$ bus. Figure 19 shows a power flow diagram for the S/C. Table 14 shows the MEL for the power system. Total power system mass is $1304 \mathrm{~kg}$ which includes margin for each component.

Table 13 shows an over view of the $10 \mathrm{~kW}_{\mathrm{e}}$ version of the Kilopower reactor. The reactor uses highly enriched ${ }^{235} \mathrm{U} / \mathrm{Mo}$ alloy. The reactor is designed such that it produces a constant temperature regardless of the amount of heat drawn from the reactor. Total reactor and shield height is about $1.4 \mathrm{~m}$ with a mass of $482 \mathrm{~kg}$. Heat is transported from the reactor via 18 heat pipes to the 8 Stirling convertors. Heat rejection is accomplished by Ti/water heat pipes connecting the cold end of the convertors to radiators. The total allowed radiation dose is $1 \times 10^{11}$ neutrons $/ \mathrm{cm}^{2}$ and $100 \mathrm{krad}$ at a distance of $15 \mathrm{~m}$ from the payload end of the shadow shield.

Figure 18 shows how four of the eight Stirling convertors are attached to both the reactor and the radiator. Total reactor thermal power is $31 \mathrm{~kW}_{\text {th }}$ with an overall conversion efficiency of $25 \%$ to provide $8 \mathrm{~kW}$ to the $\mathrm{S} / \mathrm{C}$ bus. Figure 19 shows a power flow diagram for the S/C. Table 14 shows the MEL for the power system. Total power system mass is $1304 \mathrm{~kg}$ which includes margin for each component.

Table 13. Top Level Characteristics of Fission Power System

\begin{tabular}{lc}
\hline \hline \multicolumn{1}{c}{ Item } & Kilopower \\
\hline Nuclear fuel & $93 \%$ enriched, solid cast U-235 Mo alloy \\
Reactor & Fast spectrum, Be reflector, single centered control rod \\
Thermal output & $43.3 \mathrm{~kW}_{\text {th }}$ \\
Heat transport & $1100 \mathrm{~K}$ passive Na heat pipes \\
Power conversion & Stirling convertors \\
Design life & $10 \mathrm{yr}$ \\
Environment & Multi-Mission Capable \\
Voltage range & $28 \pm 6 \mathrm{~V} \mathrm{DC}$ \\
BOM/EOM DC power & $420 \mathrm{~W}$ \\
Voltage range & $28 \pm 6 \mathrm{~V} \mathrm{DC}$ \\
Conversion efficiency & $30 \%$ \\
Reactor and Shield Mass & $482 \mathrm{~kg}$ \\
Volume (reactor) & $32 \mathrm{~cm}$ diameter by $50 \mathrm{~cm}$ tall cylinder \\
\hline \hline
\end{tabular}



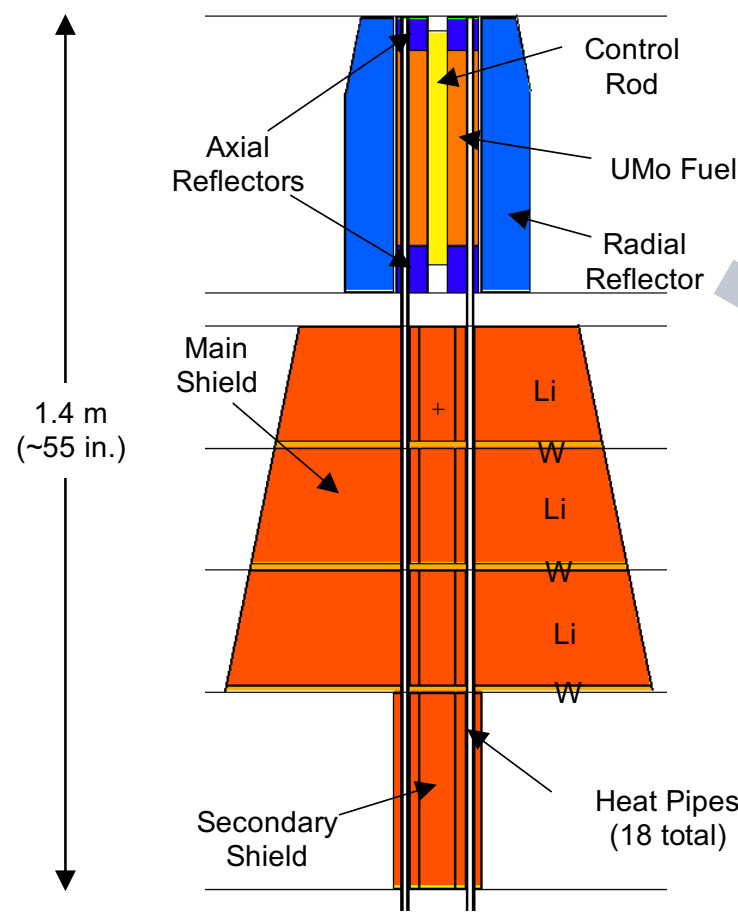

Reactor Cross-Section

Safety Collar Annulus (collar not shown)

Radial

Reflector

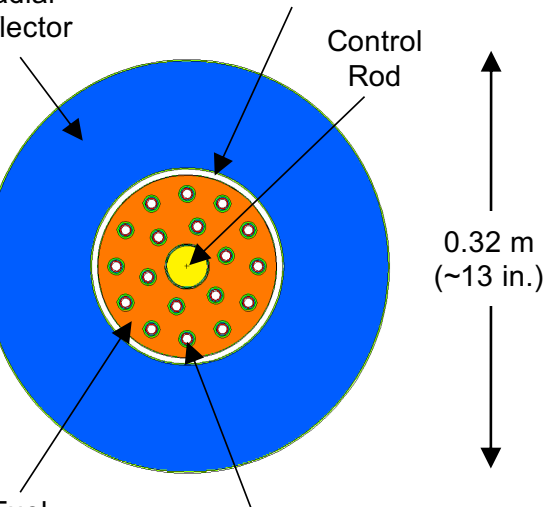

Figure 17. Reactor Core and Shield of $10 \mathrm{~kW}$ Kilopower design

\begin{tabular}{|c|}
\hline Reactor power $\left(\mathrm{W}_{\mathrm{th}}\right) \ldots \ldots$ \\
\hline Waste heat $\left(\mathrm{W}_{\mathrm{th}}\right) \ldots \ldots \ldots \ldots$ \\
\hline Thermal loss $\left(\mathrm{W}_{\mathrm{th}}\right)$. \\
\hline Conversion power $\left(\mathrm{W}_{\mathrm{e}}\right)$.. \\
\hline Electrical loss $\left(\mathrm{W}_{\mathrm{e}}\right) \ldots \ldots \ldots$ \\
\hline System useable power $\left(\mathrm{W}_{\mathrm{e}}\right) \ldots \ldots$ \\
\hline Conversion efficiency................... \\
\hline System efficiency..... \\
\hline Fuel temperature $(\mathrm{K}) \ldots$ \\
\hline Stirling hot end temperature $(\mathrm{K}) \ldots \ldots \ldots \ldots . . .$. \\
\hline Stirling cold end temperature $(\mathrm{K}) \ldots$ \\
\hline Radiation average rejection temperature $(\mathrm{K}) \ldots .415$ \\
\hline Sink temperature $(\mathrm{K}) \ldots$ \\
\hline Radiator area $\left(\mathrm{m}^{2}\right) \ldots \ldots$ \\
\hline
\end{tabular}

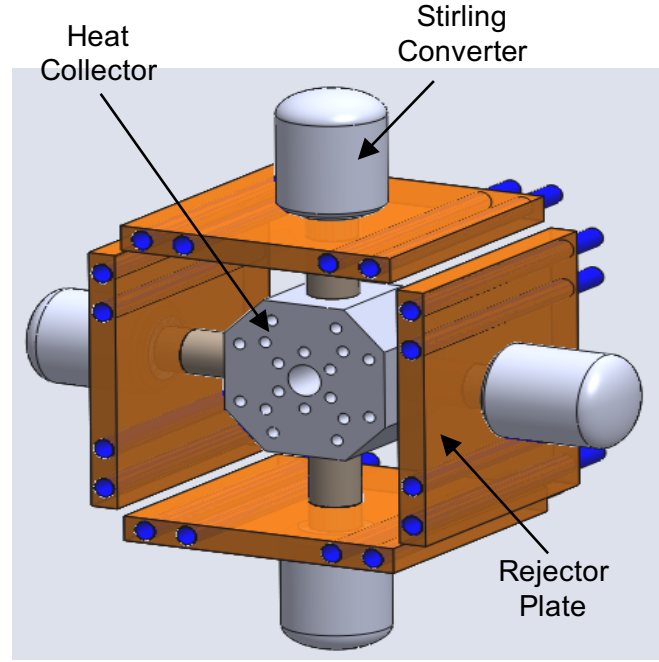

Figure 18. Stirling Attachment and Performance Summary 


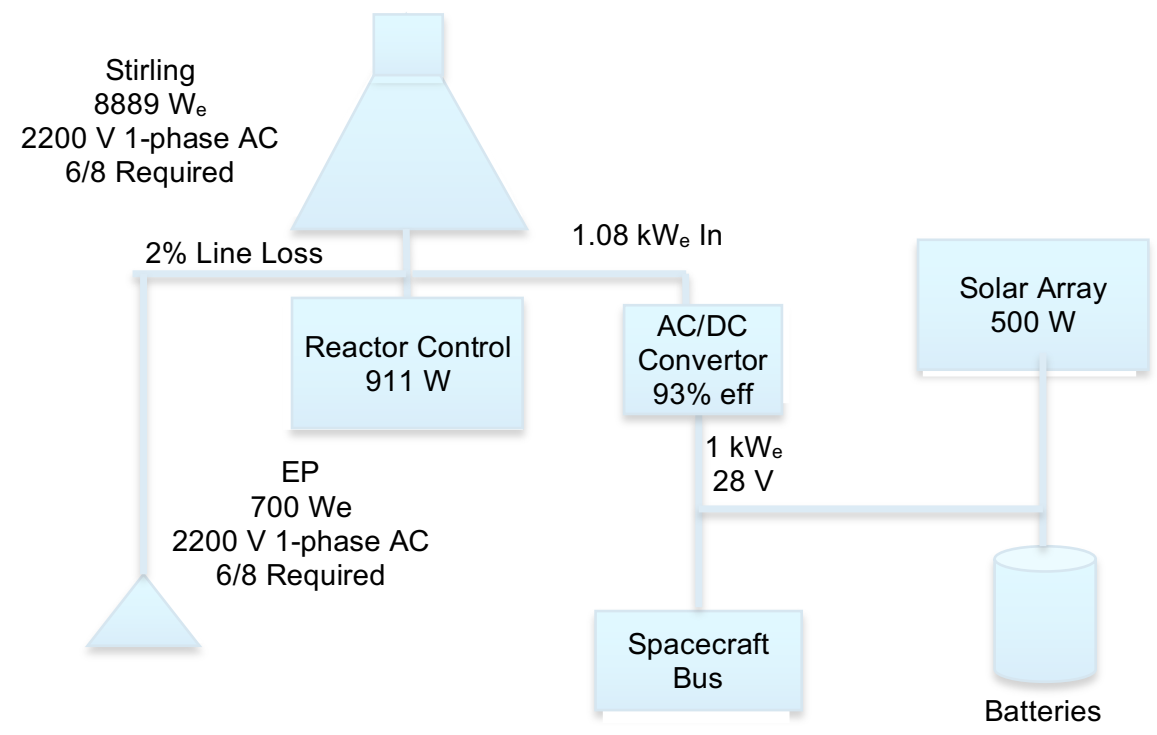

Figure 19. Power Flow from the Reactor to the Various Subsystems

Table 14. Power System MEL

\begin{tabular}{|c|c|c|c|c|c|c|}
\hline $\begin{array}{c}\text { Description } \\
\text { NEP KBOO CD-2012-77 }\end{array}$ & QTY & $\begin{array}{c}\text { Unit Mass } \\
(\mathrm{kg})\end{array}$ & $\begin{array}{c}\text { Basic Mass } \\
(\mathrm{kg}) \\
\end{array}$ & $\begin{array}{c}\text { Growth } \\
(\%) \\
\end{array}$ & $\begin{array}{c}\text { Growth } \\
\text { (kg) }\end{array}$ & $\begin{array}{c}\text { Total Mass } \\
(\mathrm{kg})\end{array}$ \\
\hline NEP Kuiper Belt Object Orbiter (KBOO) & & & 2962.19 & $6.6 \%$ & 195.84 & 3158.03 \\
\hline NEP KBOO Vehicle & & & 2962.19 & $6.6 \%$ & 195.84 & 3158.03 \\
\hline Electrical Power Subsystem & & & 1163.53 & $12.1 \%$ & 140.53 & 1304.06 \\
\hline Power Conversion & & & 220.60 & $15.0 \%$ & 33.09 & 253.69 \\
\hline Stirling & 1 & 106.70 & 106.70 & $15.0 \%$ & 16.01 & 122.71 \\
\hline Heat Collector & 1 & 76.30 & 76.30 & $15.0 \%$ & 11.45 & 87.75 \\
\hline Insulation & 1 & 25.60 & 25.60 & $15.0 \%$ & 3.84 & 29.44 \\
\hline Heat Pipe Assembly & 1 & 12.00 & 12.00 & $15.0 \%$ & 1.80 & 13.80 \\
\hline Power Management \& Distribution & & & 218.78 & $12.1 \%$ & 26.40 & 245.18 \\
\hline Controller/Cables & 1 & 80.00 & 80.00 & $15.0 \%$ & 12.00 & 92.00 \\
\hline DC PMAD & 1 & 62.00 & 62.00 & $15.0 \%$ & 9.30 & 71.30 \\
\hline Shunt Radiator & 1 & 34.00 & 34.00 & $15.0 \%$ & 5.10 & 39.10 \\
\hline Harness and Cables & 1 & 37.08 & 37.08 & $0.0 \%$ & 0.00 & 37.08 \\
\hline Solar Array & 1 & 5.70 & 5.70 & $0.0 \%$ & 0.00 & 5.70 \\
\hline Reactor and Radiation Shield & & & 482.68 & $9.3 \%$ & 44.82 & 527.49 \\
\hline Core Assembly & 1 & 178.00 & 178.00 & $15.0 \%$ & 26.70 & 204.70 \\
\hline $\mathrm{IC} \& \mathrm{C}$ & 1 & 32.00 & 32.00 & $15.0 \%$ & 4.80 & 36.80 \\
\hline Gamma Shield & 1 & 145.98 & 145.98 & $3.0 \%$ & 4.38 & 150.36 \\
\hline Neutron Shield & 1 & 83.90 & 83.90 & $3.0 \%$ & 2.52 & 86.42 \\
\hline Structure + Misc. & 1 & 42.80 & 42.80 & $15.0 \%$ & 6.42 & 49.22 \\
\hline Heat Rejection & & & 241.47 & $15.0 \%$ & 36.22 & 277.69 \\
\hline Rejector Plate & 1 & 20.50 & 20.50 & $15.0 \%$ & 3.08 & 23.58 \\
\hline Radiator & 1 & 29.20 & 29.20 & $15.0 \%$ & 4.38 & 33.58 \\
\hline Truss Assembly & 1 & 191.77 & 191.77 & $15.0 \%$ & 28.77 & 220.54 \\
\hline
\end{tabular}

4. Power Analytical Methods

The reactor and shield analysis was performed at Los Alamos National Lab using MCNP and other internal computational tools. Stirling convertor, heat rejection and other nonreactor components were modeled using Microsoft ${ }^{\circledR}$ Excel. 


\section{F. Propulsion System}

\section{Propulsion System Requirements}

Assuming that a single NEXT thruster can process $1200 \mathrm{~kg}$ of Xe only one thruster is required, but a $1+1$ configuration is used to provide single fault tolerance, thus two $6.9 \mathrm{~kW}$ NEXT thrusters are required for main propulsion. The thruster system digital control interface units (DCIU) are required to be integrated with avionics in order to save mass and reduce complexity. Thrust vectoring of the main propulsion system is required to properly orientate the vehicles thrust vector. For proper S/C attitude control, especially during coast phases, a dedicated single fault tolerant RCS system is also required.

\section{Propulsion System Assumptions}

Since thrust vectoring of the main propulsion system is required, the two axis gimbals that have been developed for use with the NEXT engine are assumed. In order to complete the mission, the primary propulsion system is required to process almost $1200 \mathrm{~kg}$ of propellant. This propellant throughput is may be beyond what the current NEXT engine accelerator grids could survive even at the high Isp setpoint $(\sim 1000 \mathrm{~kg})$, therefore advanced graphite or Ti acceleration grids are assumed in order to meet $\mathrm{S} / \mathrm{C}$ volume constraints. ${ }^{6}$ In order to take advantage of a "knee" in the density curve, Xe storage pressure is assumed to be $10.3 \mathrm{MPa}$ (1500 psia) or less if possible. A single fault tolerant RCS is assumed, and COTS components are assumed to be used as applicable in order to reduce cost and risk.

\section{Propulsion System Design and MEL}

The propulsion system for this design consists of a NEXT thruster based primary propulsion system, a hydrazine based RCS, and a Star 63F solid rocket motor. The Star 63F is not considered part of the S/C design but is instead considered part of the LV stack. Since it is required for the mission, it will be briefly discussed here.

The Star 63F is a COTS solid rocket motor manufactured by ATK. For this mission, it will need to be modified with a TVC system with a $\pm 5^{\circ}$ level of vectoring control authority. The motor has a Kevlar-epoxy composite case which, according to ATK, is to be upgraded to a graphite-epoxy composite. It also has a nominal Isp of $297.1 \mathrm{~s}$, a nominal thrust of $140.5 \mathrm{kN}$ ( $23.5 \mathrm{klbf})$, and a $120 \mathrm{~s}$ burn time.

The S/C propulsion system consists of two independent systems. There is a NEXT thruster based primary propulsion system and a hydrazine based RCS system. The primary propulsion system consists of two NEXT thrusters with integrated two axis gimbals. These engine/gimbal assemblies are mounted in a $1+1$ configuration at the aft of the $\mathrm{S} / \mathrm{C}$. These thrusters utilize Xe propellant that is stored at supercritical conditions in a single COPV tank located near the center of the S/C. The RCS thrusters are located in four pods containing four thrusters each and are located on booms at the aft of the vehicle. The location of these components is shown in Figure 20 and Figure 21.

The NEXT thrusters are $56 \mathrm{~cm}$ diameter gridded ion thrusters that utilize Xe as the propellant. They can operate from $0.6 \mathrm{~kW}$ up to $6.9 \mathrm{~kW}$, and have demonstrated an efficiency of $70 \%$ and an Isp greater than $4150 \mathrm{~s}$. While undergoing long duration testing, it has performed over 37,000 operations, processed over $630 \mathrm{~kg}$ of Xe, and has spent more than $20,000 \mathrm{hr}$ at full power. Figure 22 shows a NEXT thruster and gimbal assembly, and the thruster during operation.

The Xe propellant is stored in a single COPV (T1000 fiber based composite) tank at a pressure of 7.24 MPa (1050 psia). It is of the same design as the one used for NASA's Dawn mission but is scaled to fit the S/C bus. The Xe propellant is isolated during launch by COTS high pressure latching valves (Moog 51-170) and is conditioned during engine operation by dedicated flow control modules being developed by Vacco. Instead of the NEXT power processing using that conditions the variable power from SAs each NEXT engine string has a dedicated Direct Drive Unit (DDU) to condition the alternating current coming from the $\mathrm{S} / \mathrm{C}$ power system to the correct direct current voltage levels required by the NEXT thrusters $(\sim 1800 \mathrm{~V})$; essentially making it a fully controlled full bridge rectifier. This DDU approach is both lighter and more efficient. The thrusters, gimbals, feed system modules, and DDUs are controlled via DICUs which are integrated with the avionics. The propellant feed system has a nominal instrumentation suite and a $5 \mu \mathrm{m}$ (absolute) filter. A schematic of the primary propulsion system is shown in Figure 23.

The RCS is a hydrazine based monopropellant blow-down system utilizing nitrogen gas the pressurant. Hydrazine is stored in two ATK 80432-1 diaphragm tanks. These tanks are constructed of 6Al-4V Ti alloy and have an AF-E-322 rubber membrane. The hydrazine is delivered via nominal single fault tolerant feed system to 16 Aerojet MR-111C thrusters located in four pods containing four thrusters each. These thrusters have a nominal thrust level of $4.4 \mathrm{~N}(1.0 \mathrm{lbf})$ and a nominal Isp of $225 \mathrm{~s}$. The RCS has a nominal instrumentation suite, and insulation and heaters on the feed lines. A preliminary P\&ID of the RCS is shown in Figure 24. 


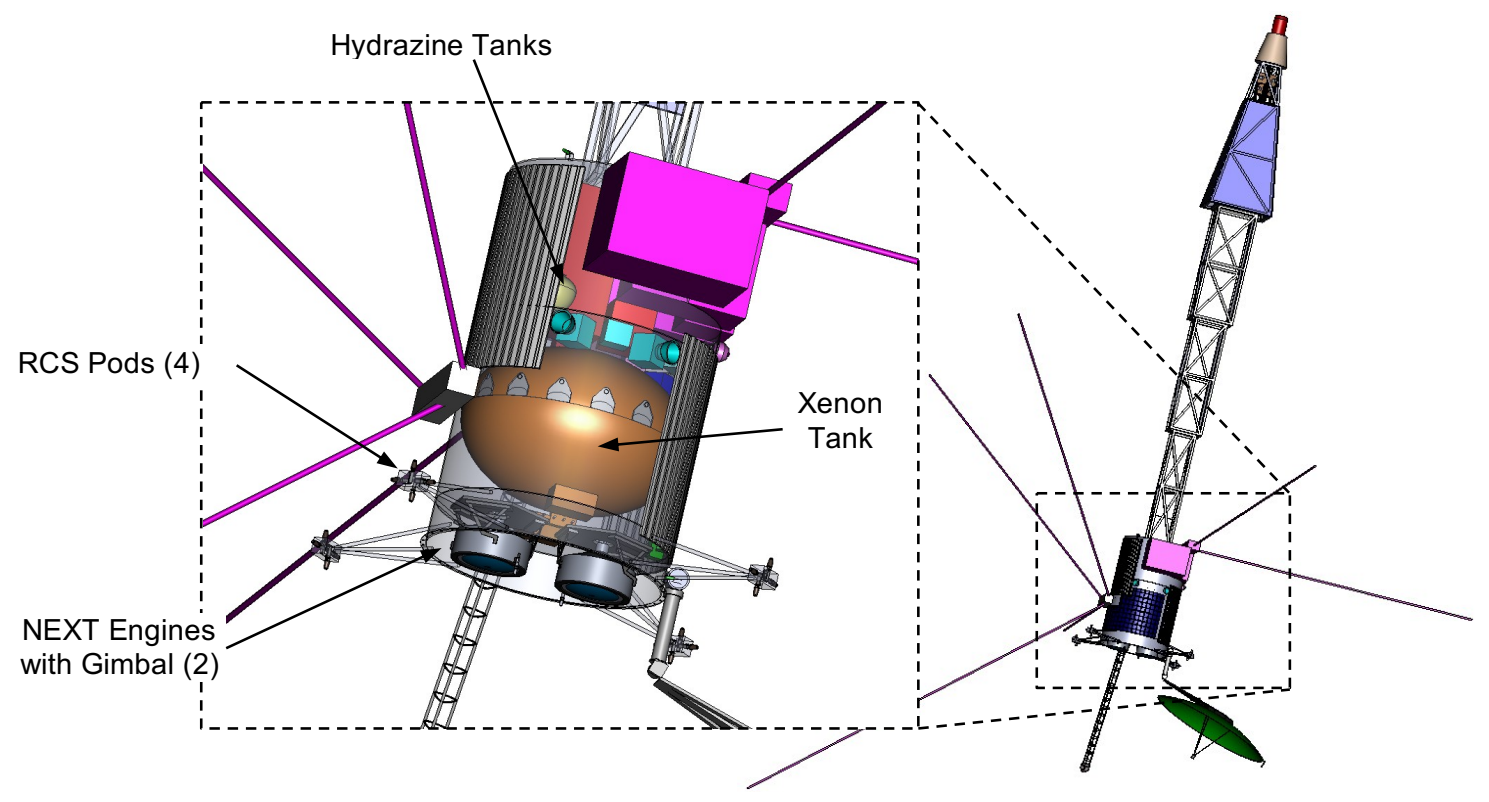

Figure 20. Propulsion System Configuration.

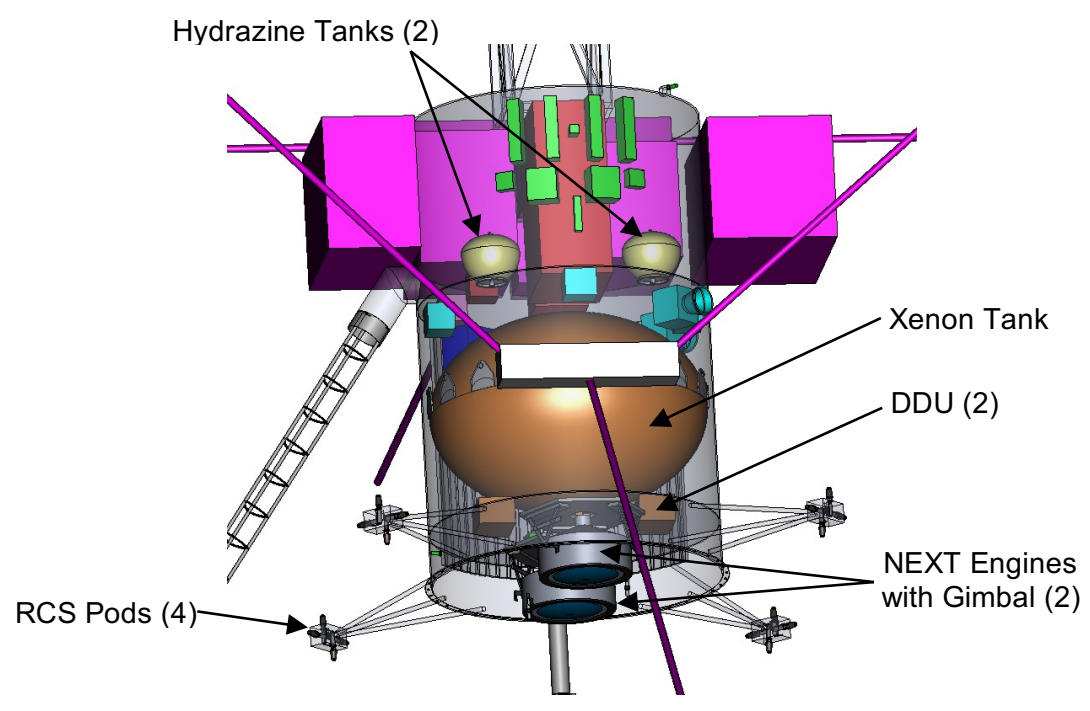

Figure 21. Propulsion System Configuration, Alternate View.

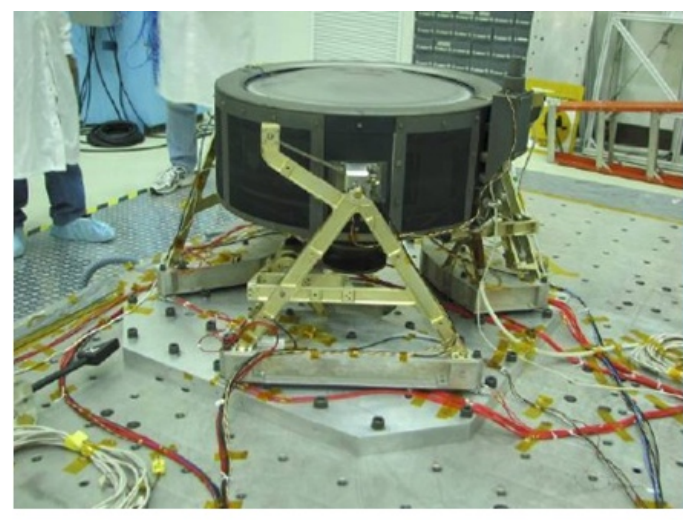

NEXT Thruster with Gimbal Assembly

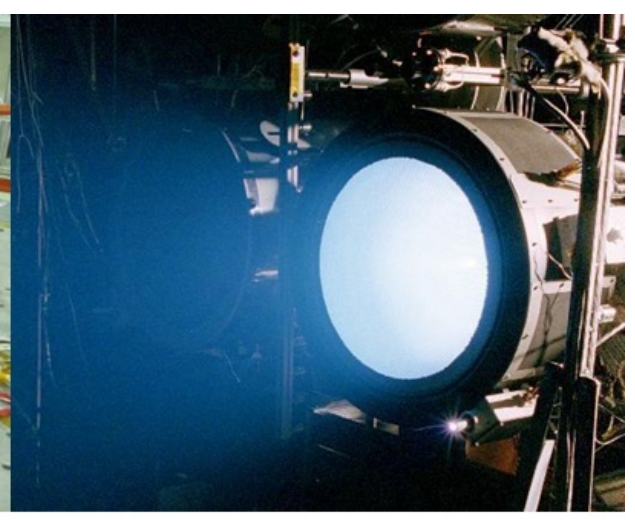

NEXT Thruster Firing

Figure 22. NEXT Thruster 


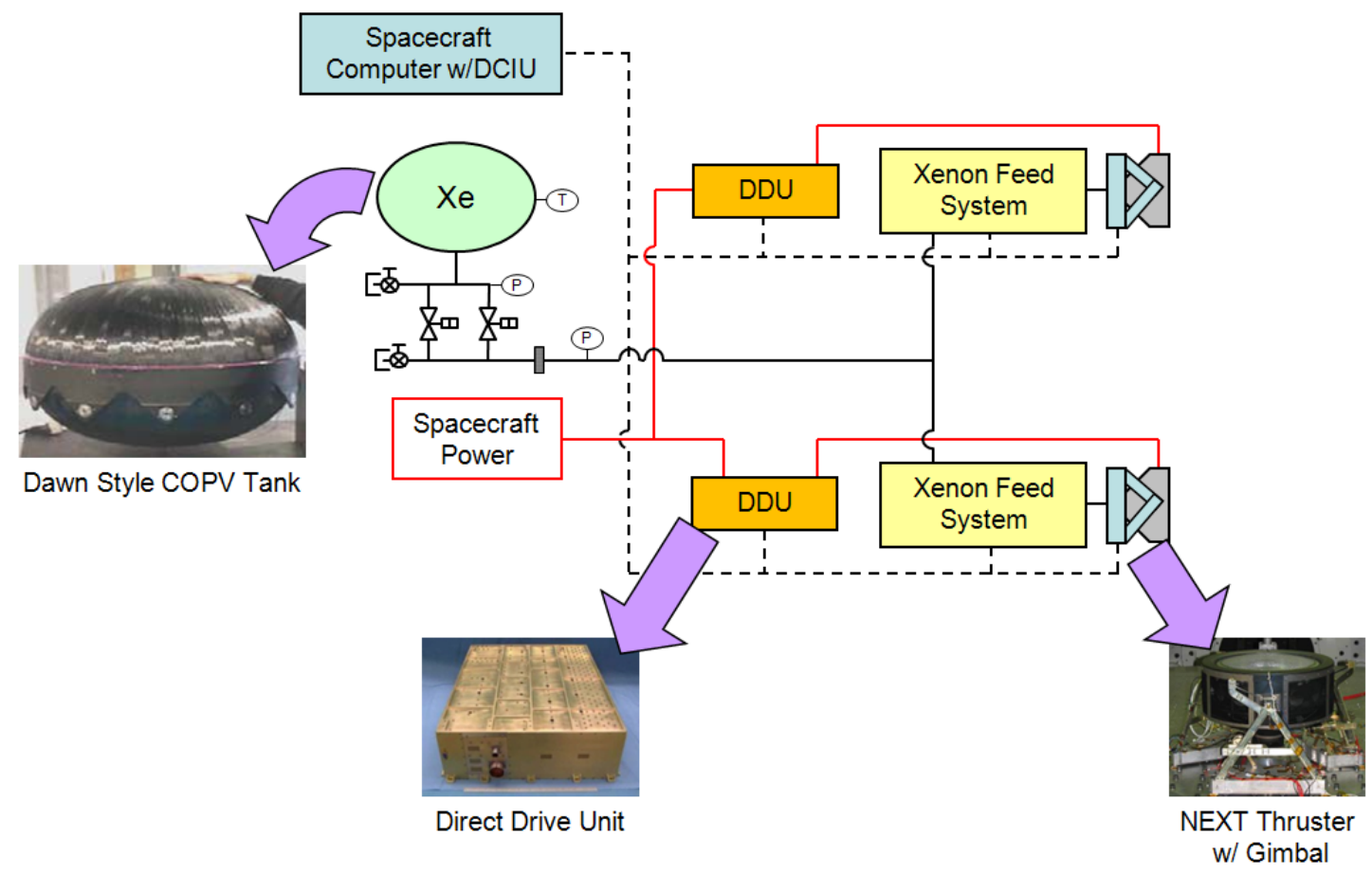

Figure 23. Primary Propulsion System Schematic
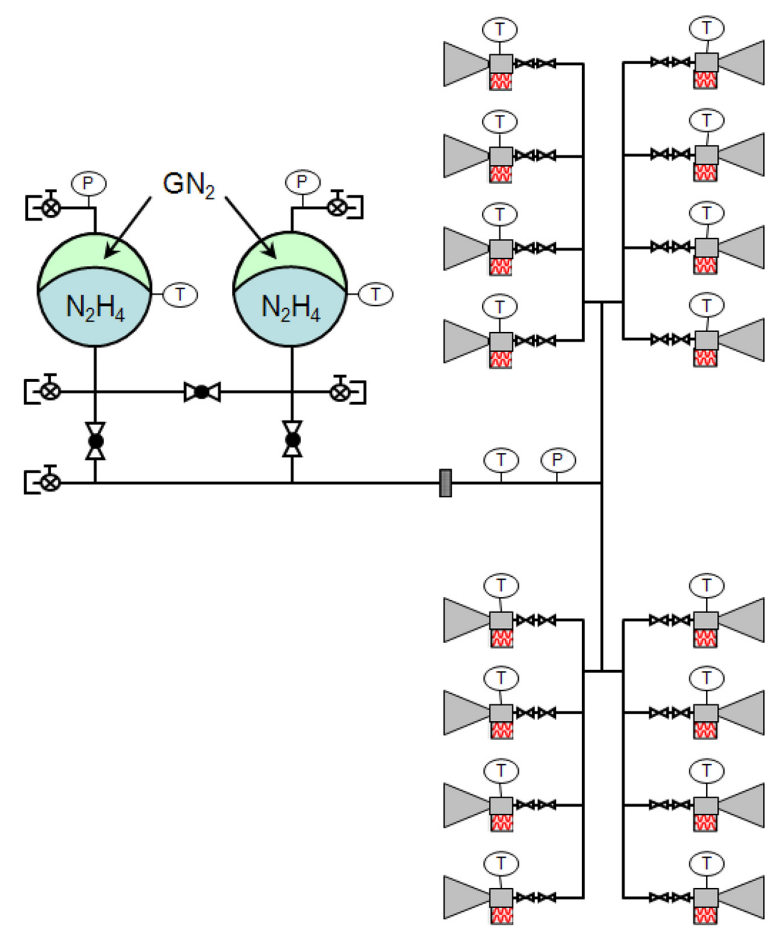

Figure 24. Preliminary RCS P\&ID

The total propellant mass is calculated using information from both the trajectory mission analysis output and internal propellant and propulsion system calculations. The three different propellants tracked in the MEL are used, performance margin, and residuals, all of which are defined, respectively, as follows:

Used: The used propellant is calculated using an ideal rocket equation. This is the propellant necessary to push the mass of the $\mathrm{S} / \mathrm{C}$ using the total mission $\Delta \mathrm{V}$ and the idealized form of the rocket equation. There is no margin on the used propellant. 
Performance Margin: The performance margin is calculated by taking a percentage of the total $\Delta \mathrm{V}$ performed by that particular propulsion system. For this analysis, $5 \%$ is used for the Xe propellant and $10 \%$ is used for the hydrazine propellant.

Residuals: The residuals are calculated by taking the total mass of the used and margin propellants and calculating a percentage of that mass. For this analysis, $1.0 \%$ is used to calculate the residual Xe mass and $3.5 \%$ is used to calculate the residual hydrazine mass.

Total propellant: The total propellant of the mission is the sum of used, margin and residuals.

$$
m_{\text {Total Propellant }}=m_{\text {used }}+m_{\text {Margin }}+m_{\text {Residuals }}
$$

These divisions of propellant are used in the calculation of dry, wet and inert mass of the S/C. A listing of all major propulsion system component masses as captured in the MEL shown in Table 15.

Table 15. Propulsion System MEL

\begin{tabular}{|c|c|c|c|c|c|c|}
\hline $\begin{array}{c}\text { Description } \\
\text { NEP KBOO CD-2012-77 }\end{array}$ & QTY & $\begin{array}{c}\text { Unit Mass } \\
(\mathrm{kg})\end{array}$ & $\begin{array}{c}\text { Basic Mass } \\
(\mathrm{kg})\end{array}$ & $\begin{array}{c}\text { Growth } \\
(\%)\end{array}$ & $\begin{array}{c}\text { Growth } \\
\text { (kg) }\end{array}$ & $\begin{array}{c}\text { Total Mass } \\
(\mathrm{kg}) \\
\end{array}$ \\
\hline NEP Kuiper Belt Object Orbiter (KBOO) & & & 2962.19 & $6.6 \%$ & 195.84 & 3158.03 \\
\hline NEP KBOO Vehicle & & & 2962.19 & $6.6 \%$ & 195.84 & 3158.03 \\
\hline Propulsion (Chemical Hardware) & & & 17.70 & $5.9 \%$ & 1.05 & 18.75 \\
\hline Primary Chemical System Hardware & & & 9.28 & $6.3 \%$ & 0.59 & 9.87 \\
\hline Main Engine Hardware & & & 0.00 & 0 & 0.00 & 0.00 \\
\hline Reaction Control System Hardware & & & 9.28 & $6.3 \%$ & 0.59 & 9.87 \\
\hline RCS Engines & 16 & 0.33 & 5.28 & $2.0 \%$ & 0.11 & 5.39 \\
\hline RCS Thruster Subassembly & 4 & 1.00 & 4.00 & $12.0 \%$ & 0.48 & 4.48 \\
\hline Propellant Management (Chemical) & & & 8.42 & $5.5 \%$ & 0.47 & 8.89 \\
\hline Main Engine Propellant Management & & & 8.42 & $5.5 \%$ & 0.47 & 8.89 \\
\hline Fuel Tanks & 2 & 2.72 & 5.44 & $2.0 \%$ & 0.11 & 5.55 \\
\hline Feed System - regulators, valves, etc. & 1 & 2.98 & 2.98 & $12.0 \%$ & 0.36 & 3.34 \\
\hline Propulsion (EP Hardware) & & & 122.82 & $9.1 \%$ & 11.18 & 134.00 \\
\hline Primary EP System Hardware & & & 39.00 & $2.0 \%$ & 0.78 & 39.78 \\
\hline EP System Hardware & & & 39.00 & $2.0 \%$ & 0.78 & 39.78 \\
\hline Primary EP Thrusters & 2 & 12.70 & 25.40 & $2.0 \%$ & 0.51 & 25.91 \\
\hline Main Engine Gimbal & 2 & 6.80 & 13.60 & $2.0 \%$ & 0.27 & 13.87 \\
\hline Reaction Control System Hardware & & & 0.00 & 0 & 0.00 & 0.00 \\
\hline Power Processing Unit (PPU) & & & 15.80 & $12.0 \%$ & 1.90 & 17.70 \\
\hline DDU & 2 & 7.00 & 14.00 & $12.0 \%$ & 1.68 & 15.68 \\
\hline DDU Cabling & 2 & 0.90 & 1.80 & $12.0 \%$ & 0.22 & 2.02 \\
\hline Propellant Management (EP) & & & 68.02 & $12.5 \%$ & 8.50 & 76.52 \\
\hline EP Propellant Tank system & & & 68.02 & $12.5 \%$ & 8.50 & 76.52 \\
\hline Xe Propellant Tanks & 1 & 62.40 & 62.40 & $12.0 \%$ & 7.49 & 69.89 \\
\hline Feed System & 1 & 5.62 & 5.62 & $18.0 \%$ & 1.01 & 6.63 \\
\hline Propellant (EP) & & & 1223.22 & $0.0 \%$ & 0.00 & 1223.22 \\
\hline Main Propellant (EP) & & & 1223.22 & $0.0 \%$ & 0.00 & 1223.22 \\
\hline Primary EP Propellant Used & 1 & 1156.64 & 1156.64 & 0.00 & 0.00 & 1156.64 \\
\hline Primary EP Propellant Residuals (Unused) & 1 & 8.75 & 8.75 & $0.0 \%$ & 0.00 & 8.75 \\
\hline Primary EP Propellant Performance Margin (Unused) & 1 & 57.83 & 57.83 & $0.0 \%$ & 0.00 & 57.83 \\
\hline
\end{tabular}

\section{Propulsion System Analytical Methods}

The methods used to design the propulsion system involve using a mix of published values, empirical data, and analytical tools. Published values and empirical data are used wherever possible, with analytical tools being employed as necessary. Empirical data is used to aid in the mass and size estimation of similar systems when published values are not available. Numerous analytical tools are used in this analysis, including NIST tables and fluid property codes, as well as custom tools developed from basic physical relationships and conservation equations with empirical based inclusions for real life hardware requirements (mounting bosses, flanges, etc.). 
The Xe tank is designed by setting the outer diameter of the tank so that it fit within the S/C bus. Using the geometric ratios from the Dawn tank, the volume is calculated, and the required tank pressure is obtained by dividing the total propellant load (useable, margin, and residuals) by the tank volume and using the resulting density to obtain the supercritical Xe pressure at $300 \mathrm{~K}$. This process does require some iteration to accommodate for tank wall thickness, which is a function of both tank storage pressure and launch loads.

\section{G. Structures and Mechanisms}

\section{Structures and Mechanisms Requirements}

The NEP KBOO structures must contain the necessary hardware for avionics, communications, propulsion, and power. The structural components must be able to withstand applied loads from the LV and operational maneuvers and provide minimum deflections, sufficient stiffness, and vibration damping. A $5 \mathrm{~g}$ axial acceleration and a maximum $2 \mathrm{~g}$ lateral acceleration is anticipated during the launch. The goal of the design is to minimize weight of the components that comprise the structure of the $\mathrm{S} / \mathrm{C}$ bus and must also fit within the physical confines of the LV.

The mechanisms are required to function for single events or continuously throughout the mission, depending on the types of mechanisms. The separation mechanism must release the S/C upon completion of the LV's part of the trajectory in a single short duration event. The power system boom drive must deploy the boom and lock it in place.

\section{Structures and Mechanisms Description}

The main bus consists of shells and flanges forming a thrust tube design, which is assumed to provide the optimum architecture for housing the necessary operational hardware. The thrust tube is easily adapted to the LV. The flanges and bus wall material are of the Al Li alloy, 2090, from the Metallic Materials Properties Development and Standardization (MMPDS). ${ }^{7}$ Figure 25 illustrates a transparent view of the main bus.

The analysis performed in this study assumed a maximum axial load from launch of $5.5 \mathrm{~g}$ with an $\mathrm{S} / \mathrm{C}$ mass of approximately $3000 \mathrm{~kg}(6600 \mathrm{lb})$. A safety factor of 1.4 is assumed as per the NASA standard, NASA-STD-5001B, ${ }^{8}$ for a prototype design.

The secondary structures consist of composite sandwich structure decks for supporting the tanks and propulsion hardware. The decks use carbon fiber reinforced polymer matrix composite face sheets with a Hexcel Al honeycomb core. T-300 3k/934 plain weave fabric from the Department of Defense "Composite Materials Handbook," is assumed for the face sheets. Additional supports consist of Al tubular members for the attachment of radiators and propulsion hardware. Lastly, the power system boom uses a space frame architecture with square tubular members.

Mechanisms are utilized to separate the S/C from the Star 63F upper stage and to deploy the power system boom. A Lightband is assumed for the separation mechanism. Screw drives and rails are assumed for the power system boom.

An additional installation mass is typically added for each subsystem in the mechanisms section of the structural subsystem. These installations are modeled using $4 \%$ of the CBE dry mass of each of the subsystems. The $4 \%$ magnitude for an initial estimate compares well with values reported by Heineman ${ }^{10}$ for various manned systems. This is to account for attachments, bolts, screws, and other mechanisms necessary to attach the subsystem elements to the bus structure, and not bookkept in the individual subsystems.

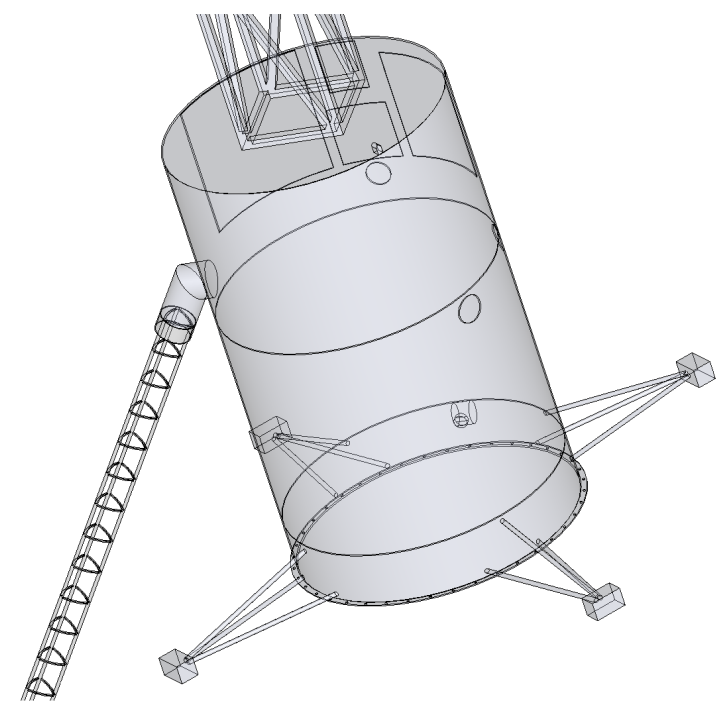

Figure 25. A transparent view of the main bus structure. 


\section{Structures and Mechanisms Design and MEL}

Many of the components are internally mounted to the NEP. The internal hardware includes components for communications and tracking; control and data handling; guidance, navigation, and control; electrical power; and propulsion. Placement of the tanks and various boxes can be observed.

Thermal radiators and arrays are fastened to the outer surface of the thrust tube structure. The main components of the propulsion hardware and thrusters are also on the outside of the structure. Separation mechanisms are used between the $\mathrm{S} / \mathrm{C}$ and the $\mathrm{LV}$. Figure 26 shows the $\mathrm{S} / \mathrm{C}$ with a transparent bus so the various components can be seen.

Table 16 shows the expanded MEL for the structural subsystem, note that the $191 \mathrm{~kg}$ power truss mass is carried in the power system portion of the MEL.

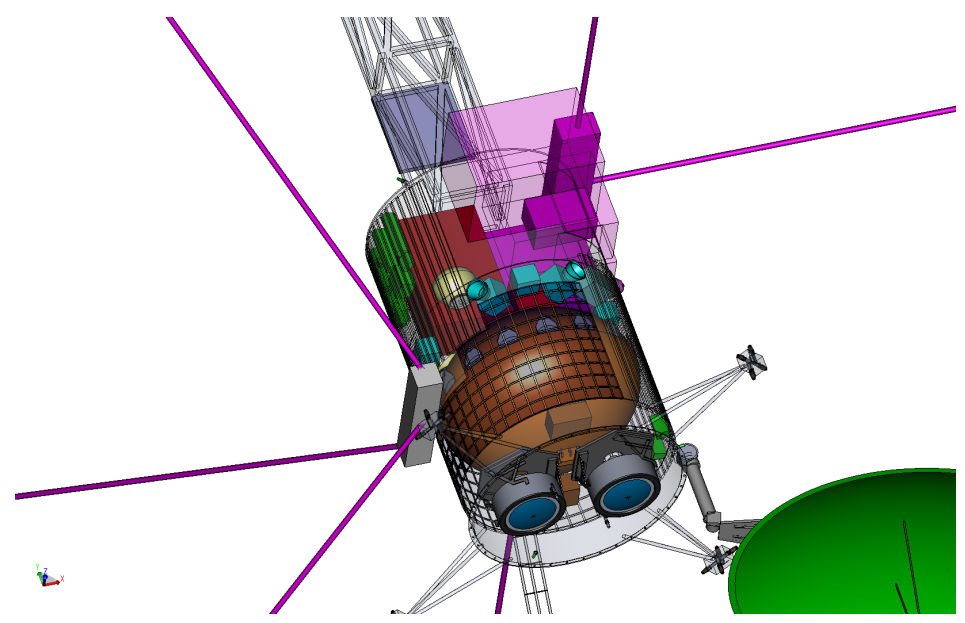

Figure 26. A view of the mounted hardware within the bus of the NEP.

Table 16. NEP KBOO Structures MEL

\begin{tabular}{lcccccc}
\hline $\begin{array}{c}\text { Description } \\
\text { NEP KBOO CD-2012-77 }\end{array}$ & $\begin{array}{c}\text { QTY } \\
\text { Unit Mass } \\
(\mathbf{k g})\end{array}$ & $\begin{array}{c}\text { Basic Mass } \\
(\mathbf{k g})\end{array}$ & $\begin{array}{c}\text { Growth } \\
(\mathbf{\%})\end{array}$ & $\begin{array}{c}\text { Growth } \\
(\mathbf{k g})\end{array}$ & $\begin{array}{c}\text { Total Mass } \\
(\mathbf{k g})\end{array}$ \\
\hline NEP Kuiper Belt Object Orbiter (KBOO) & & & 2962.19 & $6.6 \%$ & 195.84 & 3158.03 \\
NEP KBOO Vehicle & & & 2962.19 & $6.6 \%$ & 195.84 & 3158.03 \\
$\quad$ Structures and Mechanisms & & & 119.32 & $18.0 \%$ & 21.48 & 140.79 \\
$\quad$ Structures & & & 69.14 & $18.0 \%$ & 12.44 & 81.58 \\
$\quad$ Primary Structures & & & 69.14 & $18.0 \%$ & 12.44 & 81.58 \\
$\quad$ Main Body & 1 & 69.14 & 69.14 & $18.0 \%$ & 12.44 & 81.58 \\
Mechanisms & & & 50.18 & $18.0 \%$ & 9.03 & 59.21 \\
$\quad$ Adaptors and Separation & & 6.42 & $18.00 \%$ & 1.16 & 7.57 \\
$\quad$ Separation mechanism to ELV (Stays with S/C) & 1 & 6.42 & 6.42 & $18.00 \%$ & 1.16 & 7.57 \\
$\quad$ Installations & & & 43.76 & $18.00 \%$ & 7.88 & 51.64 \\
$\quad$ GN\&C Installation & 1 & 1.02 & 1.02 & $18.00 \%$ & 0.18 & 1.20 \\
$\quad$ Command and Data Handling Installation & 1 & 1.45 & 1.45 & $18.00 \%$ & 0.26 & 1.71 \\
$\quad$ Communications and Tracking Installation & 1 & 2.39 & 2.39 & $18.00 \%$ & 0.43 & 2.82 \\
$\quad$ Electrical Power Installation & 1 & 31.72 & 31.72 & $18.00 \%$ & 5.71 & 37.43 \\
$\quad$ Thermal Control Installation & 1 & 2.23 & 2.23 & $18.00 \%$ & 0.40 & 2.63 \\
$\quad$ EP Propulsion Installation & 1 & 4.95 & 4.95 & $18.00 \%$ & 0.89 & 5.84 \\
\hline \hline
\end{tabular}

\section{Structures and Mechanisms Analytical Methods}

Preliminary structural analysis and modeling were performed using the given launch load of $5.5 \mathrm{~g}$ and dimensions of the proposed S/C bus. The thrust tube structure of the NEP bears the load of the S/C of approximately $3000 \mathrm{~kg}$ $(6600 \mathrm{lb})$ under the maximum launch acceleration of $5.5 \mathrm{~g}$. The resulting stress within the thrust tube is $18.7 \mathrm{MPa}$ 
(2.71 ksi). The allowable stress is $150 \mathrm{MPa}(21.8 \mathrm{ksi})$ which is limited by the material yield strength and a safety factor of 1.4. The resulting margin is 7.0.

The power system boom was evaluated also. In the stowed position it is assumed that the largest box bears the launch loads while the boom is stowed. Approximately $1000 \mathrm{~kg}(2200 \mathrm{lb})$ are supported with a launch load of $5.5 \mathrm{~g}$ axial acceleration. Assuming the axial loads are evenly distributed among the four legs of the box the calculated stress is $57 \mathrm{MPa}(8.3 \mathrm{ksi})$. With a yield limited allowable stress of $150 \mathrm{MPa}(21.8 \mathrm{ksi})$ the margin is 1.6.

An additional installation mass was added for each subsystem in the mechanisms section of the structural subsystem. These installations were modeled using $4 \%$ of the CBE dry mass for each of the subsystems.

\section{H. Thermal Control}

Objective: To provide a design and sizing of the thermal system for the NEP KBOO main S/C. Thermal design for the reactor power system is in the power system section. Because of the difference in operating temperature, this is a separate thermal system than that used for the power system thermal control. This system will include estimating thermal system component masses, volumes and power consumption. The sizing the thermal system components is based on their worst-case operational environment.

For the thermal system there is a worst case hot and worst case cold environment. Both of these are used to size different aspects of the system. Solar Intensity and view angle as well as the view to warm bodies such as the Earth and S/C SAs are used to determine the worst case hot and cold conditions. The worst case warm conditions will occur near Earth whereas the worst case cold will be in deep space.

The thermal system modeling provides power and mass estimates for the various aspects of the vehicle thermal control system based on a number of inputs related to the vehicle geometry, flight environment and component size. The thermal systems modeled are

- Radiator panels

- Thermal control of propellant lines \& tanks

- Spacecraft insulation

- Avionics, PPM and PMAD cooling

- Heaters

- Temperature sensors, controllers, switches, data acquisition

\section{Thermal Requirements}

The thermal requirements for the mission were to provide a means of cooling and heating of the S/C equipment in order to remain within their maximum and minimum temperature requirements during Earth orbit, transit and orbit insertion at the $\mathrm{KBO}$.

The S/C utilized a nuclear reactor power system. The reactor unit has its own integrated radiator system and therefore did not require any cooling form the thermal control system. The thermal control system was used to maintain the temperature of the internal electronics and payload as well as the DDUs for the thrusters. The maximum heat load to be rejected by the thermal system was $1500 \mathrm{~W}$. The desired operating temperature for the electronics was $300 \mathrm{~K}$ and $250 \mathrm{~K}$ for the $\mathrm{S} / \mathrm{C}$ structure. The $\mathrm{S} / \mathrm{C}$ was required to maintain these temperature requirements at the various stages of the mission, Earth orbit and transit to the Kuiper belt. Electric heaters mounted near critical components within the vehicle supplied internal heat. All outer surfaces were covered with either multilayer insulation (MLI) or thermal control paint depending on their temperature requirements.

\section{Thermal Assumptions}

The assumptions utilized in the analysis and sizing of the thermal system were based on the operational environment, including low Earth orbit and transit to the Kuiper belt. The following assumptions were utilized to size the thermal system.

- The maximum angle of the radiator to the Sun was $30^{\circ}$.

- The radiator temperature was $300 \mathrm{~K}$.

- View factor of the radiator to the $\mathrm{S} / \mathrm{C}$ was 0.25 .

- A redundant radiator was not used in the design.

- MLI was used to insulate the $\mathrm{S} / \mathrm{C}$ to minimize heat transfer to and from the surroundings.

- Electric heaters and the waste heat from the electronics were used to maintain the desired internal temperature of the $\mathrm{S} / \mathrm{C}$.

- Since excess power is available from the reactor, louvers were not utilized with the radiator. Variable conductance heat pipes were utilized to regulate the heat transfer to the radiator. 
Table 17 identifies the $\mathrm{S} / \mathrm{C}$ specification, assumptions and requirements for the thermal system design and operation.

Table 17. Thermal Design Specifications, Assumptions and Requirements

\begin{tabular}{ll}
\hline \hline Item & Value \\
\hline Spacecraft outside dimensions & Length $2 \mathrm{~m}$ \\
& Width $1.6 \mathrm{~m}$ \\
Electronics cold plates & 5 at $0.1 \mathrm{~m}$ by $0.1 \mathrm{~m}$ \\
Engine PPU Cold Plates & 2 at $0.15 \mathrm{~m}$ by $0.15 \mathrm{~m}$ \\
Waste heat load to be rejected & Main S/C: $1500 \mathrm{~W}$ \\
Spacecraft and propellant tanks operational temperature & $300 \mathrm{~K}$ \\
Environment & Operational environment: $1 \mathrm{AU}$ hot, 40 AU cold \\
Radiator and view factors & Max $30^{\circ}$ angle to the Sun \\
& View factor to the $\mathrm{S} / \mathrm{C} \& \mathrm{SAs}: \mathrm{S} / \mathrm{C} ; 0.25$ \\
\hline \hline
\end{tabular}

\section{Thermal Design and MEL}

The thermal system is used to remove excess heat from the electronics and other components of the system as well as provide heating to thermally sensitive components throughout the mission.

Excess heat is collected from a series of stainless steel cold plates located throughout the interior of the S/C. Electronics and other temperature sensitive components are mounted to the cold plates to regulate their temperature. Heat is extracted from the cold plate by heat pipes, which are integral to the plate's design. Multiple redundant heatpipe lines are used between each cold plate and the radiator. Each cold plate has four heat pipes connecting it to the radiator. The details on the cold plates are given in Table 19.

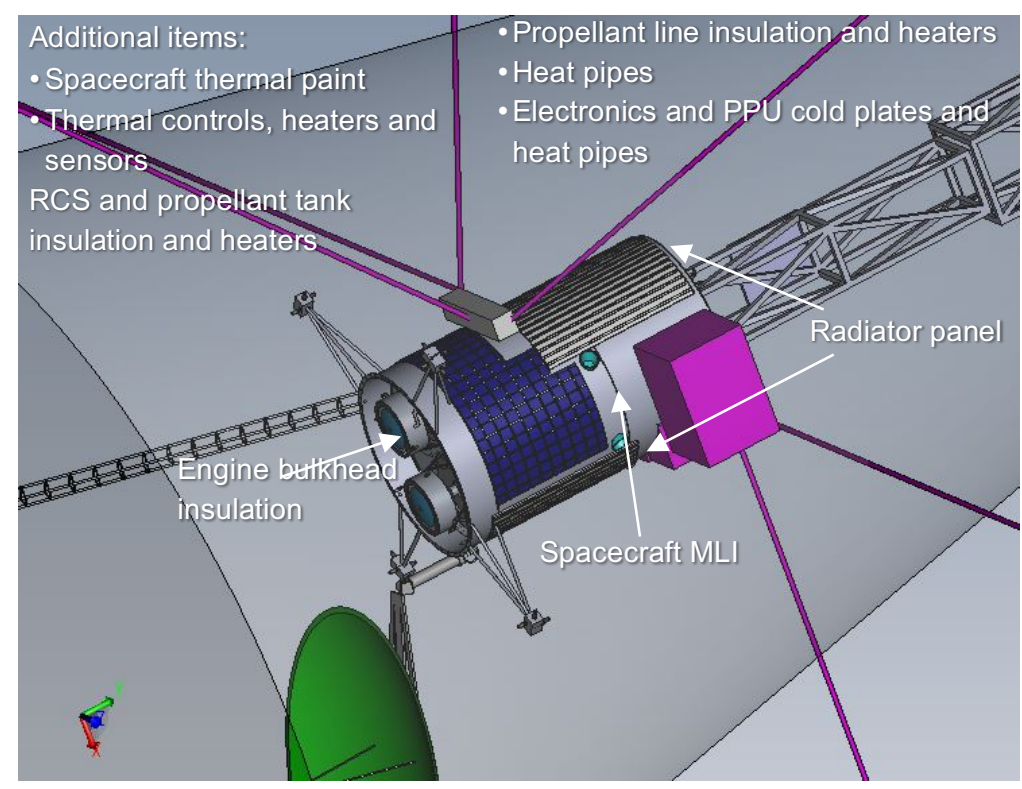

Figure 27. NEP KBOO Main Thermal System Components 


\section{Thermal Analysis: Radiator Sizing}

- The radiator panel area for the main $\mathrm{KBOO} \mathrm{S} / \mathrm{C}$ was sized based on the worst case warm operating condition of $1 \mathrm{AU}$.

- The radiator sizing was based on an energy balance analysis of the area needed to reject the identified heat load to space. From the area a series of scaling equations were used to determine the mass of the radiator. The main $\mathrm{S} / \mathrm{C}$ radiator is a body mounted design.

- Because of the operational profile of the $\mathrm{S} / \mathrm{C}$ and the amount of power available during operation, louvers were not utilized on the radiators to limit heat loss. This reduced the radiator mass and the required effective radiator area.

Table 18. Radiator Specifications

\begin{tabular}{lc}
\hline \hline \multicolumn{1}{c}{ Variable } & Value \\
\hline Radiator solar absorptivity & 0.14 \\
Radiator emissivity & 0.84 \\
Radiator Sun angle & $70^{\circ}$ \\
Radiator operating temperature & $300 \mathrm{~K}$ \\
Total radiator dissipation power & $3000 \mathrm{~W} \mathrm{~S} / \mathrm{C} 120 \mathrm{~W}$ antenna \\
\hline \hline
\end{tabular}

The heat pipes utilized are variable conductance heat pipes. This type of heat pipe can adjust the boiling point of the internal working fluid by varying the internal pressure within the heat pipe. This allows the heat pipe to be effectively turned off under conditions when excess heat generated is needed to warm the $\mathrm{S} / \mathrm{C}$ interior instead of being rejected to deep space. Water is utilized as the working fluid within the heat pipe due to the selected operating temperature of $300 \mathrm{~K}$.

\section{Thermal Analysis: PMAD Cooling}

- Sizing and mass estimates for the heat transfer components used to collect and move heat from the electronics and engine PPUs to the radiators. The components of the system included:

\section{- Cold plates}

- Heat pipes

- The cold plates also incorporated heaters in order to maintain the desired electronics temperature throughout the mission.

Table 19. Cold Plate and Heat Pipe Specifications

\begin{tabular}{lc}
\hline \hline \multicolumn{1}{c}{ Variable } & Value \\
\hline Cooling plate and line material & $\mathrm{Al}$ \\
Cooling plate and line material density & $2,770 \mathrm{~kg} / \mathrm{m}^{3}$ \\
Number of cooling plates & 5 electronics, 2 PPU \\
Cooling plate length & $0.1 \mathrm{~m}$ electronics, $0.15 \mathrm{PPU}$ \\
Cooling plate width & $0.1 \mathrm{~m}$ electronics, $0.15 \mathrm{PPU}$ \\
Cooling plate thickness & $5 \mathrm{~mm}$ \\
\hline \hline
\end{tabular}

The heat pipes transfer heat from the cold plates to the radiator, which radiates the excess heat to space. The radiator rejects heat by radiation heat transfer between the radiator and surroundings. Items that are hotter than the radiator will provide an energy input to the radiator and must be accounted for in its sizing. The radiator is sized based on an energy balance between the incoming radiation from these "hot" sources and the view to deep space. This energy balance is illustrated in Figure 28.

Using the energy balance a radiator area of $4.68 \mathrm{~m}^{2}$ was needed to reject the $1500 \mathrm{~W}$ of excess heat at the $1 \mathrm{AU}$ worst-case warm operating environment. From the required area a series of scaling equations were used to determine the mass of the radiator. The radiator is separated into the following components: panel, coating, tubing, header, adhesive, stringer and attachment.

To provide heat to the internal components electric heaters are mounted to the cold plates and other critical devices or components to maintain their desired temperature throughout the mission. The heaters utilized are strip heaters of 
various shapes to conform to the device being heated. An example of this type of heater is shown in Figure 28. The strip heaters are operated through the $\mathrm{S} / \mathrm{C}$ control system. Thermocouples are used to read the temperature of the various components throughout the $\mathrm{S} / \mathrm{C}$. The output of the thermocouples goes to a data acquisition system that reads and monitors the thermocouple temperatures. If the temperature on a device is too low the control system turns on a nearby heater through control switches and regulates the current to the heater to raise the temperature of the device to the desired level. Once at the correct level, the control system will turn the heater off.

MLI insulation was used to insulate the $\mathrm{S} / \mathrm{C}$ and minimize heat loss for deep space operation. MLI is constructed of a number of layers of metalized material with a nonconductive spacer between the layers. The metalized material has a low absorptivity that resists radiative heat transfer between the layers.

- MLI was used to cover the exterior exposed portion of the S/C. The insulation was analyzed to determine the required number of layers and the corresponding mass and heat loss needed to maintain $300 \mathrm{~K}$ interior $\mathrm{S} / \mathrm{C}$ temperature. A tradeoff was performed between the insulation mass and the required heater power.

- The insulation model was based on heat transfer from the $\mathrm{S} / \mathrm{C}$ interior through the insulation layers to space.

- 40 AU Deep space thermal environment was used to size the insulation.

The insulation can be molded to conform over the exterior of the $\mathrm{S} / \mathrm{C}$ or any individual component. This enables it to be utilized as an effective insulating material on most $\mathrm{S} / \mathrm{C}$ configurations. For this $\mathrm{S} / \mathrm{C}$ design 25 layers of MLI were used to wrap the complete exterior of the vehicle.

The mass breakdown of the thermal system for the NEP KBOO is shown in

Table 21.

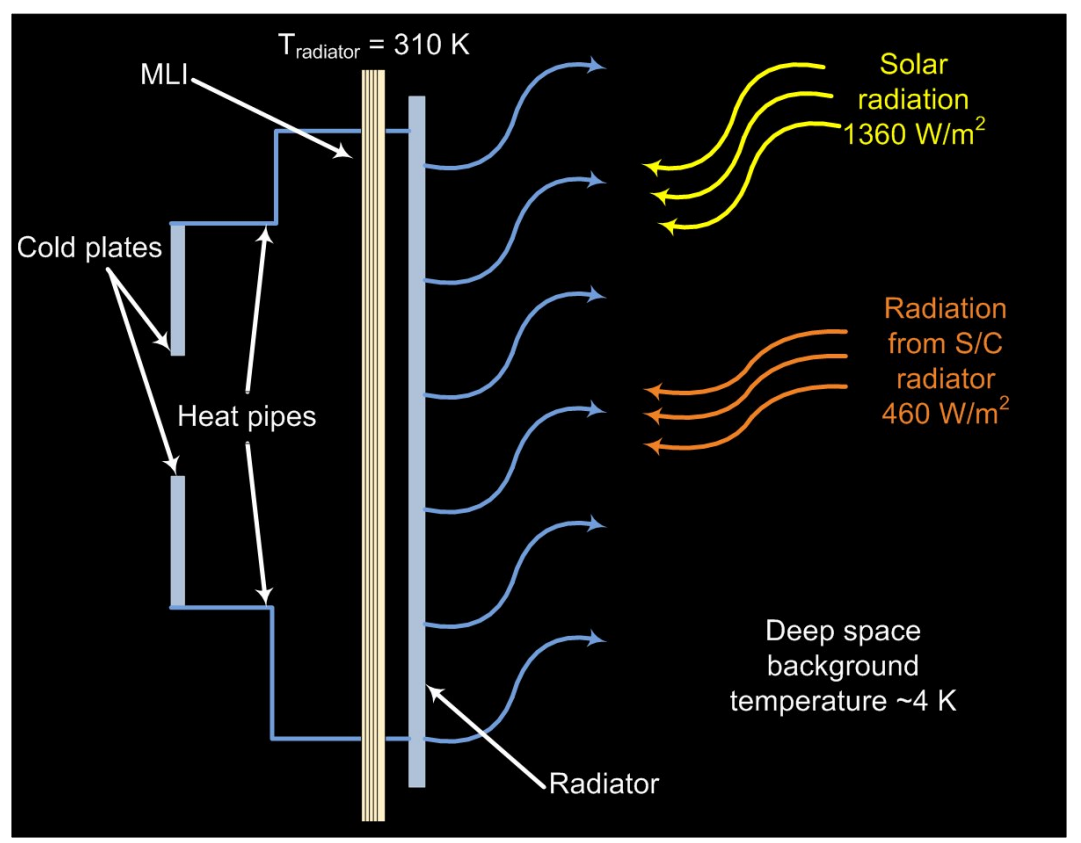

Figure 28. Radiator Energy Balance

Table 20. MLI Specifications

\begin{tabular}{lc}
\hline \hline \multicolumn{1}{c}{ Variable } & Value \\
\hline Spacecraft MLI Material & $\mathrm{Al}$ \\
Spacecraft MLI Material Density & $2,770 \mathrm{~kg} / \mathrm{m}^{3}$ \\
MLI Layer Thickness & $0.025 \mathrm{~mm}$ \\
Number of Insulation Layers & 25 \\
\hline \hline
\end{tabular}




\begin{tabular}{lc}
\hline \hline Number of Insulation Layers Bulkhead & 25 \\
MLI Layer Spacing & $1 \mathrm{~mm}$ \\
\hline \hline
\end{tabular}

Table 21. Thermal MEL

\begin{tabular}{|c|c|c|c|c|c|c|}
\hline $\begin{array}{c}\text { Description } \\
\text { NEP KBOO CD-2012-77 }\end{array}$ & QTY & $\begin{array}{c}\text { Unit Mass } \\
\text { (kg) }\end{array}$ & $\begin{array}{l}\text { Basic Mass } \\
(\mathrm{kg})\end{array}$ & $\begin{array}{c}\text { Growth } \\
(\%)\end{array}$ & $\begin{array}{c}\text { Growth } \\
\text { (kg) }\end{array}$ & $\begin{array}{c}\text { Total Mass } \\
(\mathbf{k g})\end{array}$ \\
\hline NEP Kuiper Belt Object Orbiter (KBOO) & & & 2962.19 & $6.6 \%$ & 195.84 & 3158.03 \\
\hline NEP KBOO Vehicle & & & 2962.19 & $6.6 \%$ & 195.84 & 3158.03 \\
\hline Thermal Control (Non-Propellant) & & & 72.13 & $0.3 \%$ & 0.21 & 72.34 \\
\hline Active Thermal Control & & & 2.85 & $7.4 \%$ & 0.21 & 3.06 \\
\hline Heaters & 7 & 0.20 & 1.40 & $15.0 \%$ & 0.21 & 1.61 \\
\hline Thermal Control/Heaters Circuit & 2 & 0.20 & 0.40 & $0.0 \%$ & 0.00 & 0.40 \\
\hline Data Acquisition & 1 & 1.00 & 1.00 & $0.0 \%$ & 0.00 & 1.00 \\
\hline Thermocouples & 5 & 0.01 & 0.05 & $0.0 \%$ & 0.00 & 0.05 \\
\hline Passive Thermal Control & & & 68.48 & $0.0 \%$ & 0.00 & 68.48 \\
\hline Heat Sinks & 5 & 0.14 & 0.69 & $0.0 \%$ & 0.00 & 0.69 \\
\hline Heat Pipes & 5 & 1.08 & 5.40 & $0.0 \%$ & 0.00 & 5.40 \\
\hline Radiators & 1 & 36.39 & 36.39 & $0.0 \%$ & 0.00 & 36.39 \\
\hline MLI & 1 & 17.83 & 17.83 & $0.0 \%$ & 0.00 & 17.83 \\
\hline Thermal Coatings/Paint & 1 & 0.44 & 0.44 & $0.0 \%$ & 0.00 & 0.44 \\
\hline Spacecraft Engine MLI & 1 & 3.54 & 3.54 & $0.0 \%$ & 0.00 & 3.54 \\
\hline PPU cold Plates & 2 & 0.90 & 1.80 & $0.0 \%$ & 0.00 & 1.80 \\
\hline PPU Heat Pipes & 2 & 1.20 & 2.40 & $0.0 \%$ & 0.00 & 2.40 \\
\hline Semi-Passive Thermal Control & & & 0.80 & $0.0 \%$ & 0.00 & 0.80 \\
\hline Louvers & 0 & 0.00 & 0.00 & $0.0 \%$ & 0.00 & 0.00 \\
\hline Thermal Switches & 4 & 0.20 & 0.80 & $0.0 \%$ & 0.00 & 0.80 \\
\hline
\end{tabular}

\section{IV.NEP and REP Comparison}

Comparing the NEP and REP S/C shows some interesting differences (Table 22). From Figure 29 it is quite evident that the NEP option is physically larger and requires a deployment for operation. Operating within the shadow of the reactor also restricts the placement of science and communications compared to the REP version. Despite this physical size difference the mass of the NEP vehicle is only $20 \%$ heavier than the REP and has twice the power for EP which allows for both vehicles to carry the same science and reach the KBO in the same time (the heavier NEP vehicle launches to a slightly lower excess velocity but can catch up easily). The specific power of the radioisotope is slightly better than the fission system at $\left(5 \mathrm{~W}_{\mathrm{e}} / \mathrm{kg}\right.$ vs. $7 \mathrm{~kW} \mathrm{e} / \mathrm{kg}$ ) but similar. Besides the challenges of handling and flying radioisotope versus fission systems (discussed elsewhere ${ }^{11}$ ) the amount and type of nuclear material is the biggest difference..$^{10}$ At $27 \mathrm{~kg}$ of Pu the load of the REP vehicle is about half that of Cassini but published production rates of $\mathrm{Pu}$ for NASA missions are now set at $1.5 \mathrm{~kg} / \mathrm{yr}$; which would require almost two decades of exclusive production if rates are not increased. $75 \mathrm{~kg}$ of ${ }^{235} \mathrm{U}$ fuel is currently is currently available. ${ }^{11}$ Ultimately the use of REP or NEP will depend upon the availability of $\mathrm{Pu}$ versus the availability of $10 \mathrm{~kW}$ fission reactors. In this final comparison the NEP may have an advantage if $10 \mathrm{~kW}$ fission reactors are developed for supporting crew bases on the Moon and Mars and can be modified for NEP vehicles. 


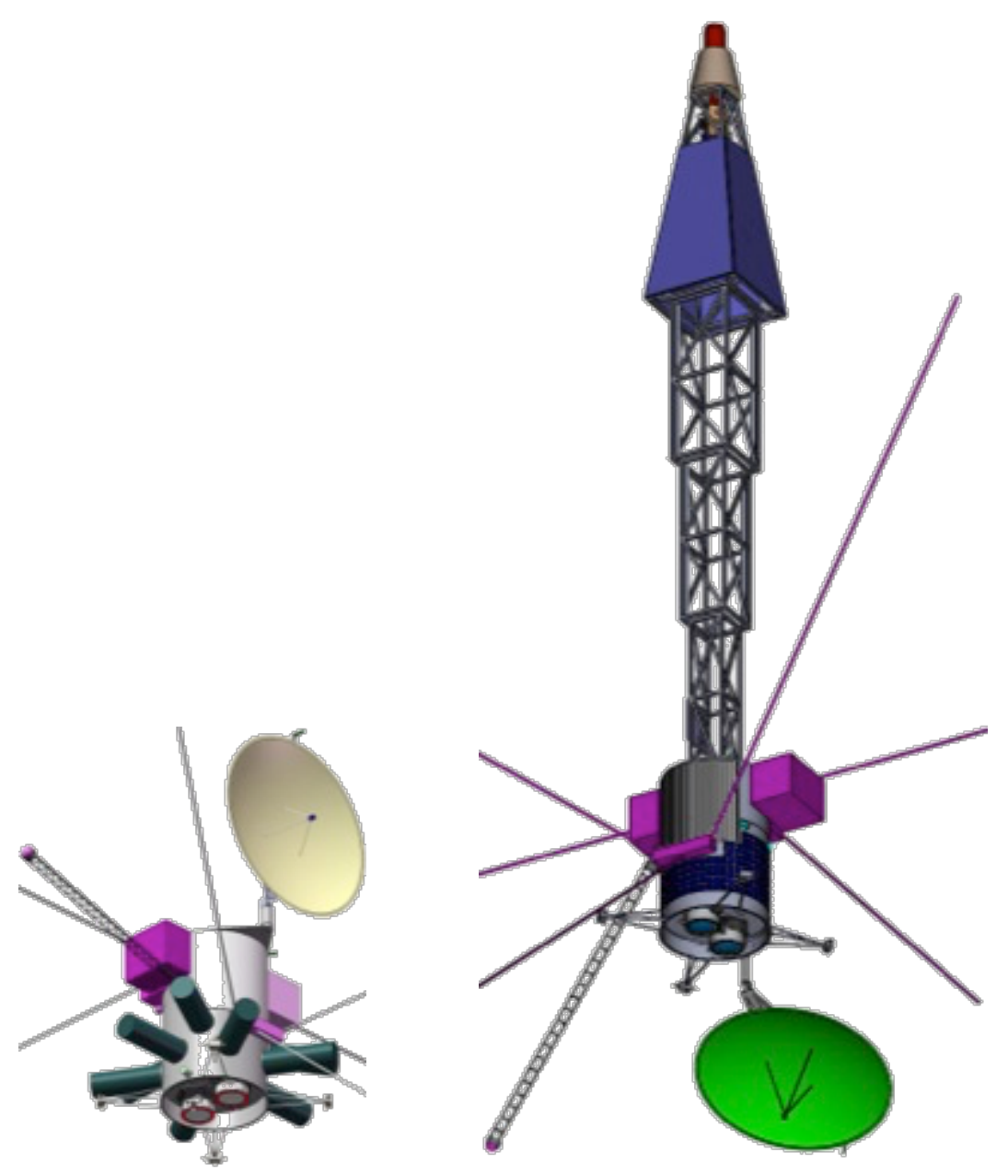

Figure 29. The $3 \mathrm{~kW}$ REP and the $8 \mathrm{~kW}$ NEP KBOO Side by Side

Table 22. Comparison of REP and NEP KBOO Parameters

\begin{tabular}{lcc}
\hline \hline \multicolumn{1}{c}{ Attribute } & REP KBOO & NEP KBOO \\
\hline Science and Trip Time & $100 \mathrm{~kg} \mathrm{CBE} / 16 \mathrm{yr}$ trip/1 yr science & $100 \mathrm{~kg} \mathrm{CBE} / 16 \mathrm{yr}$ trip/1 yr science \\
Launcher & DIVH/Star 63 & DIVH/Star 63 \\
Launch Mass & $3100 \mathrm{~kg}$ & $3700 \mathrm{~kg}$ \\
Power: Level (EOL)/Mass & Nine, $550 \mathrm{~W} \mathrm{SRG,} 4000 \mathrm{~W}_{\mathrm{e}} / 782 \mathrm{~kg}$ & Single Fast Reactor, Stirling Convertors \\
(alpha) & $(5 \mathrm{We} / \mathrm{kg})$ & $8000 \mathrm{~W} / 1162 \mathrm{~kg}(7 \mathrm{We} / \mathrm{kg})$ \\
Electric Propulsion & $1+13000 \mathrm{~W} \mathrm{NEXT} \mathrm{Ion,} 1200 \mathrm{~kg} \mathrm{Xe}$ & $1+17000 \mathrm{~W} \mathrm{NEXT} \mathrm{Ion,} \mathrm{Direct} \mathrm{Drive,}$ \\
(Thrust/weight) & $(6 \mathrm{~m} / 3 \mathrm{~m})$ & $\sim 1200 \mathrm{~kg} \mathrm{Xe}$ \\
Height (Deployed / Launch) & $\sim 27 \mathrm{~kg}{ }^{238} \mathrm{Pu}$ & $(16 \mathrm{~m} / 7 \mathrm{~m})$ \\
Nuclear material & & $\sim 75 \mathrm{~kg} 93 \%$ enriched ${ }^{235} \mathrm{U}$ \\
\hline \hline
\end{tabular}

\section{V.Summary and Conclusions}

The NEP KBOO orbiter conceptual design demonstrates that small KBOs can be orbited by using existing EP technology powered by a self-operated, low power nuclear power system. Performance of the NEP system compared very well to the REP S/C option with similar trip times, payloads and launch masses. The primary difference between the systems ultimately was the power systems size, mass, and fuel. The ultimate availability of large amounts of ${ }^{238} \mathrm{Pu}$ compared to that of $10 \mathrm{~kW}$ kilopower systems will decide which is used for eventual use for such deep space orbiters. 


\section{VI.Acknowledgements}

This work was sponsored by the NASA Radioisotope Power Systems Office and performed by the NASA COMPASS team with support from the Los Alamos National Lab. The authors wish to heartily thank all three groups for their input and support of this work.

\section{References}

${ }^{1}$ Proceedings of Nuclear and Emerging Technologies for Space 2011 Albuquerque, NM, February 7-10, 2011 Paper 3487.

${ }^{2}$ Marc A. Gibson, David I. Poston, Patrick McClure, Thomas Godfroy, James Sanzi and Maxwell H. Briggs, "The Kilopower Reactor Using Stirling TechnologY (KRUSTY) Nuclear Ground Test Results and Lessons Learned,” 2018 International Energy Conversion Engineering Conference.

${ }^{3}$ Marc A. Gibson, Steven Oleson, David I. Poston, Patrick McClure. "NASA's Kilopower Reactor Development and the Path to Higher Power Missions."

${ }^{4}$ ANSI/AIAA R-020A-1999, Recommended Practice for Mass Properties Control for Satellites, Missiles, and Launch Vehicles.

${ }^{5}$ R.N. Knauber, "Roll Torques Produced by Fixed-Nozzle Solid Rocket Motors" Journal of Spacecraft and Rockets, Vol. 33 No. 6, November-December 1996.

${ }^{6}$ Van Noord, Jonathan, "Lifetime Assessment of the NEXT Ion Thruster," 43rd AIAA/ASME/SAE/ASEE Joint Propulsion Conference \& Exhibit, AIAA 2007-5274.

${ }^{7}$ Metallic Materials Properties Development and Standardization (MMPDS) (Federal Aviation Administration, 2016).

${ }^{8}$ National Aeronautics and Space Administration, "Structural Design and Test Factors of Safety for Spaceflight Hardware." NASA-STD-5001B, 2016.

9 Department of Defense, "Composite Materials Handbook, Volume 2. Polymer Matrix Composites Material Properties." MIL-HDBK-17-2F, Jun. 17, 2002.

${ }^{10}$ Heineman Jr., W. "Design Mass Properties II: Mass Estimating and Forecasting for Aerospace Vehicles Based on Historical Data.” NASA JSC 26098, Nov. 1994.

${ }^{11}$ McNutt, Ralph, et al., Nuclear Power Assessment Study-Final TSSD-23122, Feb. 2015 